Historic, Archive Document

Do not assume content reflects current scientific knowledge, policies, or practices. 


\section{Forest \\ Health}

\section{Manaqement}

Technical Report R2 - Js

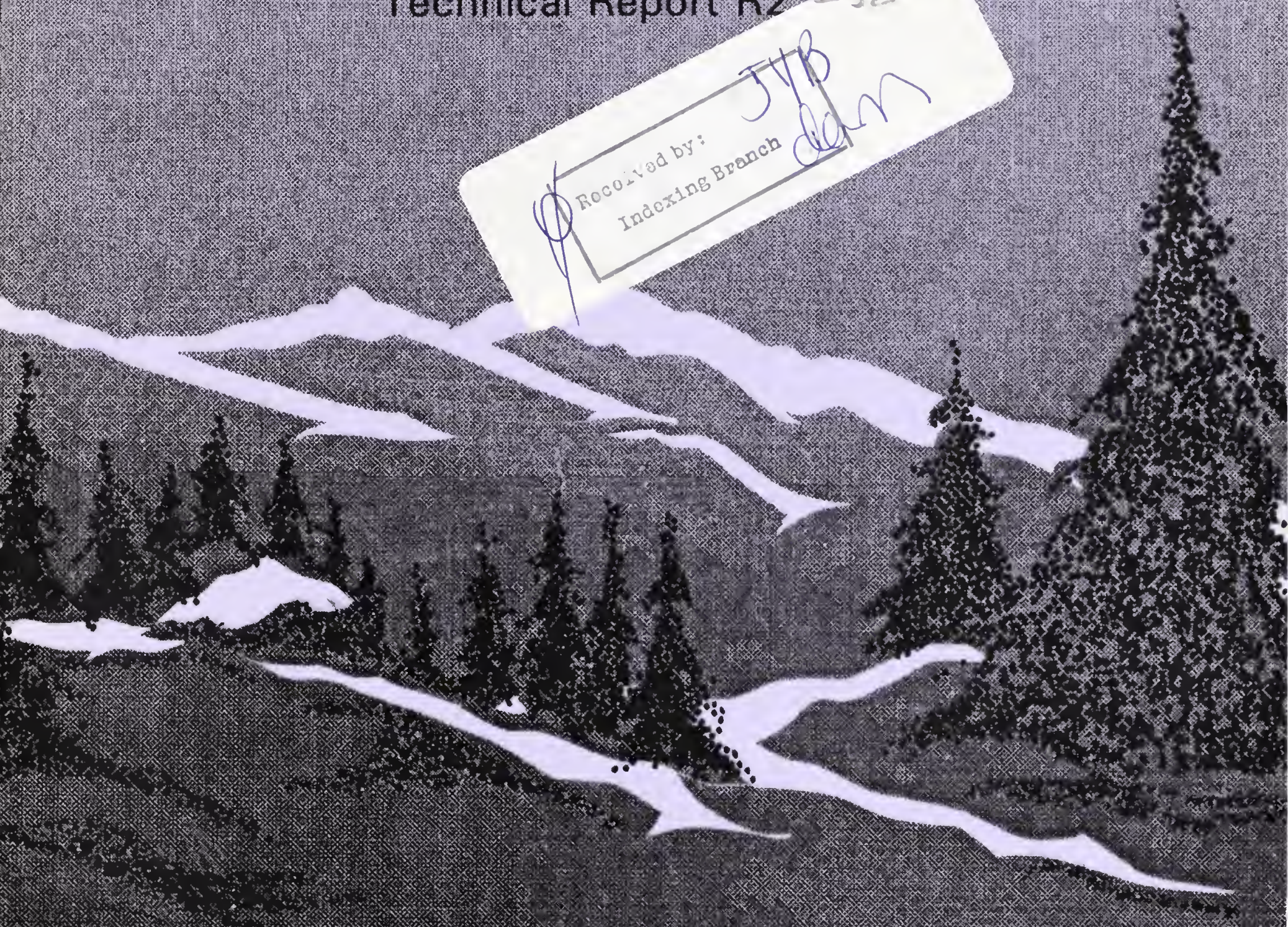

United States Department of Agriculiture
Renewable Resources Forest Health Manacement
Forest Service Rocks Mountain Reqon Denver. Colorado 
The United States Department of Agriculture (USDA) prohibits discrimination on the basis of race, color, national origin, sex, religion, age, disability, political beliefs, and marital status. (Not all basis apply to all programs). Persons with disabilities who require alternative means for communication of program information (Braille, large print, audio tape, etc.) should contact the USDA Office of Communications at $202 / 720-2791$.

To file a complaint, write the Secretary of Agriculture, U.S. Department of Agriculture, Washington, DC 20250, or call $800 / 245-6340$ (Voice), or $202 / 720-1127$ (TDD). USDA is an equal employment opportunity employer. 


\title{
COMPARISON OF RISK/HAZARD \\ RATING SYSTEMS \\ FOR MOUNTAIN PINE BEETLE \\ IN BLACK HILLS \\ PONDEROSA PINE FORESTS
}

\author{
by \\ Judith E. Pasek \\ Service Center Leader \\ Rapid City Service Center \\ and \\ Thomas M. Juntti \\ Forestry Technician \\ Rapid City Service Center
}

Technical Report R2-58

August 1997

\author{
Renewable Resources \\ Rocky Mountain Region \\ USDA Forest Service \\ 740 Simms Street \\ Golden, CO 80401
}




\section{ACKNOWLEDGMENTS}

The following personnel of the Black Hills National Forest provided electronic copies of forest inventory data needed to calculate mountain pine beetle risk/hazard ratings: Nancy Bayne and Kelly Honors (Custer/Elk Mountain Ranger District), and Elizabeth Stiller and Debra Tinker (Spearfish/Nemo Ranger District). Pam Johnson (Supervisor's Office, Black Hills National Forest) and Joe Martinetti (graduate student, South Dakota School of Mines and Technology) helped generate GIS maps of MPB risk/hazard rating outputs. John Schmid (retiree, USFS Rocky Mountain Research Station) provided valuable commentary on a draft version of this report. Cooperation and assistance from these individuals is greatly appreciated. 


\begin{abstract}
Risk/hazard rating methods for mountain pine beetle (MPB) in ponderosa pine stands were compared, based upon number of stands and acres that rated as low, medium or high risk/hazard, for four recent project areas on the Black Hills National Forest. Methods compared were the (1) Stevens model described by Stevens et al. (1980) except that the basal area threshold for high susceptibility was reduced from 150 to 120 based upon results of Schmid and Mata (1992), (2) FORPLAN model used in the Draft Revised Black Hills National Forest Plan (same as Stevens model except for assumption of only one-storied stand structure), (3) PONBUG model for the Black Hills National Forest (same as Stevens model except that data for trees $\geq 1$ inch in diameter at breast height (DBH) were used rather $\geq 5$ inches DBH), (4) Schmid model described by Schmid et al. (1994) with assumptions added to extend it to stands with quadratic mean diameter (QMD) of $<7$ inches and $>13$ inches, and (5) Schmid 5 model (same as Schmid model but recalculated using data for trees $\geq 5$ inches DBH rather than $\geq 1$ inch DBH).
\end{abstract}

Considerable differences are evident in results of the five methods. The FORPLAN model most closely resembles the Stevens model although some stand MPB risk/hazard ratings shifted from low to medium and from medium to high. In general, both stands and acres tended to increase substantially in the low MPB risk/hazard category (frequently doubling) using the PONBUG model compared to the Stevens model, while stands and acres in medium and high MPB risk/hazard categories tended to decline. However, the pattern was somewhat different for the Tollgate project where many stands had an abundance of trees $<5$ inches DBH. The Schmid model tended to shift even more stands and acres to the low MPB risk/hazard category than did the PONBUG model. In general, stands and acres in the medium and high MPB risk/hazard categories declined for the Schmid model relative to the Stevens model and its variants, with a few exceptions, most notably the high MPB risk/hazard category in the Tollgate project. The Schmid 5 model tended to shift more stands to low risk/hazard or high risk/hazard depending upon project area considered when compared to the other models. There was little consistency between stands that rated high in the Schmid 5 model and stands that rated high in the other models.

Differences in model assumptions, design, and data parameters affected MPB risk/hazard rating outcomes. Assuming only one-storied stands (FORPLAN model) increased risk/hazard ratings compared to a similar (Stevens) model that also included consideration of two-storied stands. Model results differed when using data for trees $\geq 1$ inch DBH versus for trees $\geq 5$ inches DBH and the model outcomes appeared to be affected by abundance of trees of small diameter. The Schmid model in particular may not adequately reflect MPB risk/hazard levels for uneven-aged stands and those with many trees of small DBH. There appear to be inherent differences in the way the Stevens model and its variants calculate MPB risk/hazard relative to the Schmid model and its variant that are independent of which data parameters are used for QMD and BA. The analyses of model differences presented in this report cannot identify which is closest to correct as related to MPB behavior in field settings. 


\section{INTRODUCTION}

Stevens et al. (1980) described a system for rating ponderosa pine stands in the Black Hills for susceptibility to mountain pine beetle (MPB), Dendroctonus ponderosae Hopkins, using parameters of stand structure (one- or two-storied), average diameter at breast height (DBH), and average basal area (BA). This MPB risk-rating system was incorporated into a model subroutine called PONBUG, which is linked to the Rocky Mountain Resource Inventory System (RMRIS) database used by National Forests in the Rocky Mountain Region, so that MPB risk could be automatically calculated in the program called RMSTAND. Results can be displayed in the optional field "BUG_RISK" in the table R2RIS_SITE. Values of 1, 3, and 5 indicate low, medium, and high MPB stand risk, respectively. The program was modified in 1993 for the Black Hills and Nebraska National Forests based upon results of Schmid and Mata (1992). They suggested that 120 sq. $\mathrm{ft}$. per acre may be the critical BA for separating high risk stands of susceptible-sized trees in the Black Hills, rather than $150 \mathrm{sq}$. $\mathrm{ft}$. per acre. This risk-rating program is often used by district personnel during project planning to help prioritize pine stands for thinning or harvesting.

As Rapid City Service Center staff became involved in assisting district personnel with analyses of MPB risk, it became apparent that the PONBUG model did not always produce the same results as hand calculations of the method published by Stevens et al. (1980). Closer examination of the computer program PONBUG revealed that it used average diameter and BA of trees $\geq 1$ inch QMD (quadratic mean diameter, an estimate of average stand diameter) rather than those for trees $\geq 5$ inches in diameter, as specified by Stevens et al. (1980). In addition, Stevens et al. (1980) did not define one-storied and twostoried stand structure in their rating system. In order to use the stand structure parameter in the PONBUG model, a stand was designated as two-storied if BA of trees $\geq 1$ inch QMD was $>30$ sq. $\mathrm{ft}$. per acre and number of live trees between 1 and 5 inches QMD was $>250$ per acre. Stands without these conditions were designated as one-storied. By this method, most stands in the Black Hills would be designated as one-storied. Whether or not this is an accurate portrayal of stand structures of ponderosa pine in the Black Hills is debatable. The PONBUG designations for stand structure may not represent what Stevens et al. (1980) envisioned when they described their rating system. The omission of trees smaller than 5 inches DBH from their model suggests that they considered such small trees to be unimportant for risk rating mountain pine beetle susceptibility and may also reflect a scarcity of such trees in stands of high risk. Their two-storied stands were likely to contain scattered mature trees with an understory of pole-sized trees, typical of stands found some years following shelterwood or seed tree harvesting. A quantitative means of describing such stands for use in risk/hazard rating systems for mountain pine beetle in ponderosa pine has not been developed to date.

An attempt was made to use the model of Stevens et al. (1980) as modified by the 120 BA change based upon results of Schmid and Mata (1992) in analyses of alternatives for the Proposed Revised Land and Resource Management Plan and Draft Environmental Impact Statement (EIS) for the Black Hills National Forest (1994). The FORPLAN model, used to simulate results of various management alternatives, would not handle a parameter for stand structure as described by the PONBUG model, so an assumption was made that all stands were one-storied. This was expected to shift some stands to a higher risk rating than would be produced with the BA-modified Stevens model.

Several months after the Draft Revised Plan and EIS were released for public comment, Schmid et al. (1994) published an alternative method of rating stands for MPB hazard ${ }^{1}$ in the Black Hills. A decision

\footnotetext{
${ }^{1}$ The terms 'risk' and 'hazard' and their meanings are often interchanged and confused in the literature. As used in this report, the terms both refer to the degree to which stand characteristics provide suitable habitat for development of MPB. The presence or absence of a MPB population is not considered for rating determination. Therefore, risk/hazard rating as used herein does not predict when or how frequently a given stand will be attacked by MPB. Terminology usage of rating system authors was maintained in this report; i.e., Stevens et al. (1980) used 'risk' whereas Schmid et al. (1994) used 'hazard.'
} 
was made to use this recent research in analyses for the Final Revised Plan and EIS. The method as described by Schmid et al. (1994) only pertains to stands of 7 to 13 inches mean DBH, so some assumptions had to be made for incorporation in the SPECTRUM model (a recent replacement for the FORPLAN model). It was assumed that MPB hazard would be low for all ponderosa pine stands of $<7$ inches $\mathrm{QMD}$. An assumption also was made that stands with $\mathrm{QMD}>13$ inches would have similar hazard ratings as for stands in the 7 to 13 inch DBH range (i.e., the model was extended), although there is some evidence to suggest that MPB risk/hazard may decline for stands with larger mean diameters (Lessard 1982). Data are limited to support this assertion because few stands with QMD > 13 inches are present in the Black Hills. Because of the limited acreage of large diameter ponderosa pines, the overall hazard ratings for forest planning purposes was not expected to be affected much even if the assumption was incorrect.

The release of the Schmid et al. (1994) method between publication of the draft and final versions of the Revised Forest Plan for the Black Hills National Forest raised the question of how much risk/hazard ratings from the Stevens model and its variations (PONBUG, FORPLAN) might differ from the risk/hazard ratings of the Schmid method. It also seemed appropriate to evaluate the methods and model assumptions before recommending any changes in the PONBUG program used for project analyses. The model of Stevens et al. (1980) was based upon relationships reported by Sartwell and Stevens (1975) and general observations of pine stands in the Black Hills. In contrast, Schmid et al. (1994) based their model on sets of plots of even-aged stands comprised of susceptible-sized trees that had been exposed to epidemic MPB infestations. This report compares and evaluates the risk/hazard ratings for stands in four project areas as derived from each of five methods.

\section{METHODS}

Inventory summary data generated by RMSTAND using the RMRIS database were obtained for the Soholt, Thumb, Kirk, and Tollgate project areas (Fig. 1). Data on stand location and site number, number of acres, cover type, BA and QMD of trees $\geq 1$ inch in diameter, BA and QMD of trees $\geq 5$ inches in diameter, and numbers of live trees per acre for trees $\geq 1$ inch and $\geq 5$ inches in diameter were transferred from the Data General minicomputer system to a Microsoft Excel spreadsheet on a desktop microcomputer. Number of live trees per acre between 1 and 5 inches in diameter was calculated by subtracting the number of trees per acre $\geq 5$ inches in diameter from the number of live trees per acre $\geq 1$ inch in diameter, and then stored in a column in the spreadsheet. For each of the four project areas, MPB risk/hazard was calculated for each stand of ponderosa pine cover type that had complete inventory information on BA, QMD, and number of trees per acre. For each stand, five risk/hazard rating methods were applied and compared as described below.

1. Stevens model-The risk rating system described by Stevens et al. (1980) was used with the exception that the high susceptibility threshold for BA was lowered from 150 to 120 based on results of Schmid and Mata (1992). Stand structure was classified as two-storied if BA of trees $\geq 1$ inch DBH was $>30$ sq. $\mathrm{ft}$. per acre and number of live trees between 1 and 5 inches DBH was $>250$ per acre, and otherwise classified as one-storied (same as programmed in PONBUG), because no other means of differentiating one-storied and two-storied stands of ponderosa pine for MPB risk/hazard rating purposes has been described or used. Data for mean tree diameter and basal area for trees $\geq 5$ inches DBH (designated as QMD_5 and BA_5, respectively) were used in determination of risk classes for mean stand diameter and mean stand density. Risk classes were assigned to stand characteristics as shown in Table 1. Values of risk class for each stand characteristic were multiplied together to obtain a stand risk value. A stand risk rating was then assigned depending upon stand risk value as shown in Table 2. Example: A one-storied stand (risk class $=3$ ) with QMD_5 $=8$ (risk class $=2$ ) and a BA_5 $=180$ (risk class $=3$ ) would have a stand risk value of $3 \times 2 \times 3=18$. This would just make the high stand risk rating (code 5). 


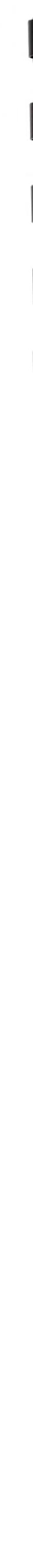




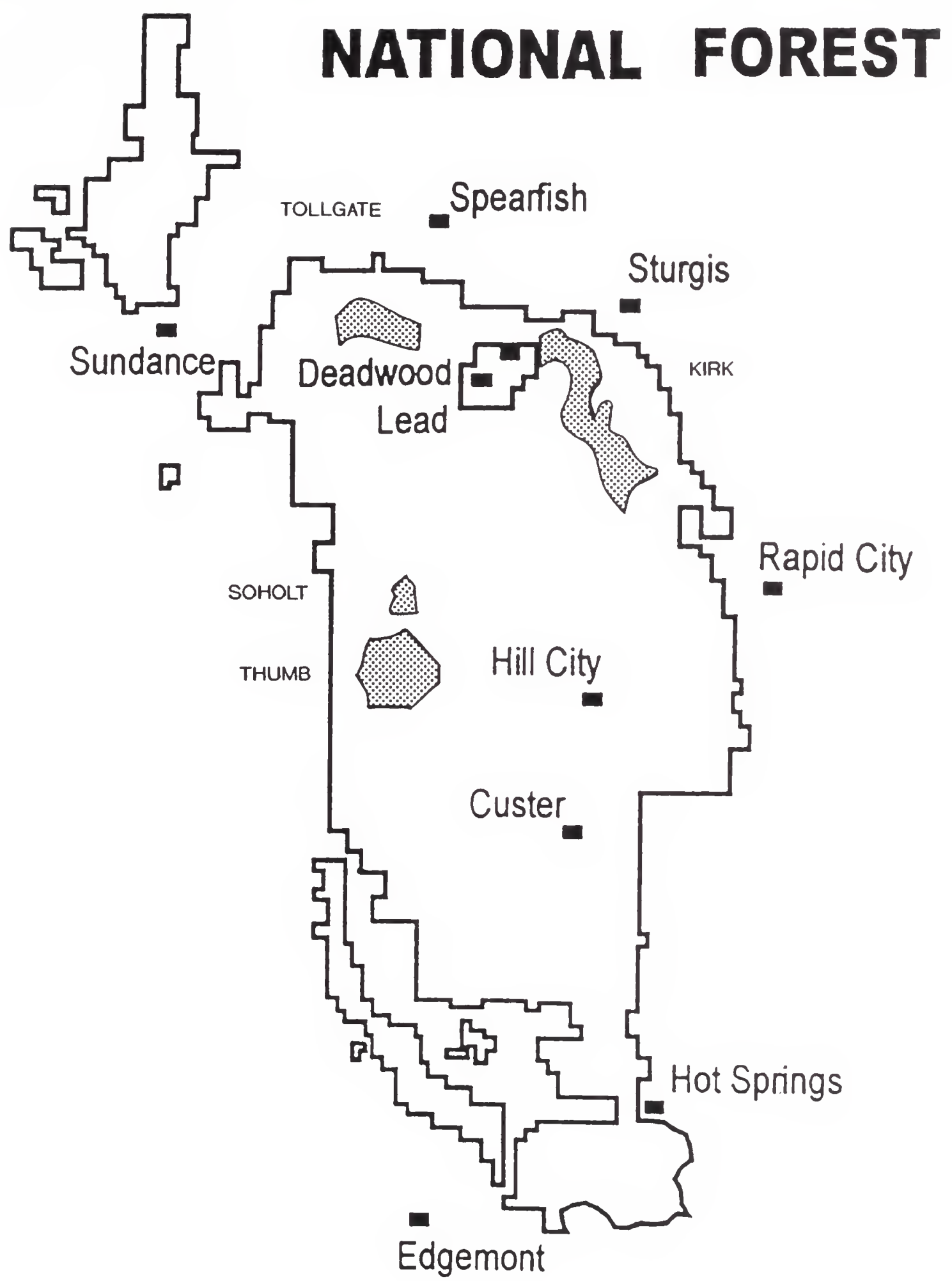

Fig. 1. Locations of four projects areas (Soholt, Thumb, Kirk and Tollgate) analyzed for mountain pine beetle risk/hazard on the Black Hills National Forest. 


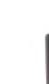


Table 1. Risk classes for mountain pine beetle risk rating of ponderosa pine stands in the Black Hills as described by Stevens et al. (1980) and modified based on results of Schmid and Mata (1992).

\begin{tabular}{|l|c|c|c|}
\hline & $1=$ low & $2=$ medium & $3=$ high \\
\hline Stand structure & -- & two-storied & one-storied \\
\hline Mean stand DBH (in.) & $<6$ & $6-10$ & $>10$ \\
\hline Stand density (BA) & $<80$ & $80-120$ & $>120$ \\
\hline
\end{tabular}

Table 2. Mountain pine beetle stand risk ratings as assigned to calculated stand risk values in Black Hills ponderosa pine (from Stevens et al. 1980).

\begin{tabular}{|c|c|}
\hline Stand risk rating & Stand risk value \\
\hline Low $=1$ & $2-6$ \\
\hline Medium $=3$ & $8-12$ \\
\hline High $=5$ & $18-27$ \\
\hline
\end{tabular}

2. FORPLAN model-Stand structure was assumed to be one-storied for all stands (i.e., risk class $=3$ ). Otherwise, calculations were the same as for the Stevens model (including use of QMD_5 and BA_5 and the values in Table 1).

3. PONBUG model-MPB risk/hazard ratings were calculated identically to the Stevens model (using values in Table 1), except that data for mean tree diameter and basal area for trees $\geq 1$ inch DBH were used (designated as QMD_1 and BA_1) instead of for trees $\geq 5$ inches DBH.

4. Schmid model-The hazard rating method described by Schmid et al. (1994) was adapted as follows. Data for mean tree diameter and basal area for trees $\geq 1$ inch DBH was used (i.e., QMD_1 and BA_1). For QMD_1 of $<7$ inches, stands were rated as low hazard (code $=1$ ). MPB hazard also rated low (code $=1$ ) if QMD_1 was $\geq 7$ inches and growing stock level (GSL) was $\leq 80$. MPB hazard rated medium (code $=3$ ) if QMD_1 was $\geq 7$ inches and GSL was $>80$ and $<120$. MPB hazard was rated high (code = 5) if QMD_1 was $>7$ inches and GSL was $\geq 120$. For stands with $\mathrm{QMD} \_1 \geq 10$ inches, BA_1 of live trees was directly substituted for GSL. For stands with QMD_1 of $\geq 7$ inches and $<10$ inches, GSL was calculated using the following formula:

$G S L=\left(80 \times B A_{-} 1\right) \div\left[\left(7.76226 \times Q M D_{-}{ }_{1}\right)+\left(0.85289 \times Q M D_{-} 1^{2}\right)-\left(0.07952 \times Q M D_{-} 1^{3}\right)-3.45624\right]$

(Carl Edminster, personal communication).

5. Schmid 5 model-MPB risk/hazard ratings were calculated identically to the Schmid model, except that data for mean tree diameter and basal area for trees $\geq 5$ inches DBH was used (i.e., QMD_5 and 

BA_5) rather than for trees $\geq 1$ inch DBH. This method was intended to allow more direct comparison of results for the Stevens and Schmid methods by basing calculations on the same data parameters.

MPB risk/hazard ratings for the PONBUG and Schmid models were overlain onto ponderosa pine stocking charts for the Black Hills to illustrate which stand conditions fall into the low, medium, and high MPB risk/hazard categories. Similar charts could not be generated for the Stevens, FORPLAN, and Schmid 5 models because stocking charts based upon data for trees $\geq 5$ inches DBH are not available.

MPB risk/hazard rating information for each model was summarized in terms of numbers and percent of stands in low, medium, and high MPB risk/hazard for each project area analyzed. Additionally, results for each model were summarized by number and percent of acres rated as low, medium, and high in cach project area.

Results of MPB risk/hazard rating calculations were transferred to ARCVIEW, a geographic information system (GIS) program, to generate maps displaying low, medium, and high risk stands using the various MPB risk/hazard rating models for each of the project areas analyzed.

\section{RESULTS AND DISCUSSION}

MPB risk rating categories as produced by PONBUG are displayed on stocking charts for Black Hills ponderosa pine for one-storied and two-storied stands (Figs. 2 and 3). Hazard rating categories of Schmid et al. (1994) including added assumptions for forest planning purposes are illustrated on the stocking chart in Fig. 4. The Schmid model has a narrower range of stand conditions that fall into the medium MPB risk/hazard category. The range of high MPB risk/hazard stand conditions is somewhat smaller for the Schmid model than for one-storied stands using PONBUG, but is considerably larger than that described for two-storied stands using PONBUG. The range of stand conditions rated as low by the Schmid model is larger than the ranges encompassed by low ratings for both one-storied and two-storied stands in PONBUG.

Considerable differences in the number and percent of stands (Table 3 ) and number and percent of acres (Table 4) rating as low, medium, and high risk/hazard for mountain pine beetle are evident for the five methods evaluated in each of the four project areas. Results of the FORPLAN model most closely resemble those of the Stevens model, with some stand ratings shifting from low to medium and from medium to high (Tables 3-5). None of the individual stand ratings shifted to lower values when comparing results for the FORPLAN model to the Stevens model. This general shift to higher MPB risk/hazard ratings was expected based upon the assumption of only single-storied stands for the FORPLAN model. The FORPLAN model, apparently because of this assumption, generally produced the greatest number of stands that rated high risk/hazard of the five models, except in the Tollgate project where it had the second highest number of stands rated as high risk/hazard (Table 3). Departures of the FORPLAN model from the Stevens model were greatest for the Tollgate and Kirk projects, located in the northern Black Hills where growing conditions are better for ponderosa pine.

Both stands and acres tended to increase substantially in the low MPB risk/hazard category (frequently doubling) using the PONBUG model compared to the Stevens model, on which the PONBUG model supposedly was based (Tables $3-4$ ). Simultaneously, stands and acres in medium and high MPB risk/hazard categories tended to decline. These relations held for the Soholt, Thumb, and Kirk projects; however, stands and acres rated as low and high MPB risk/hazard declined and medium MPB risk/hazard increased in the Tollgate project area using the PONBUG model compared to the Stevens model (Tables 3-4). Changes in individual stand ratings both increased and decreased for the PONBUG model relative to the Stevens model; however, a majority of stands that changed ratings went from medium to low MPB risk/hazard in the Soholt, Thumb, and Kirk projects while the greatest change was from low to medium MPB risk/hazard in the Tollgate project (Table 5). Differences between the Stevens and PONBUG models would be the result of using inventory data based on trees $\geq 1$ inch DBH in the 



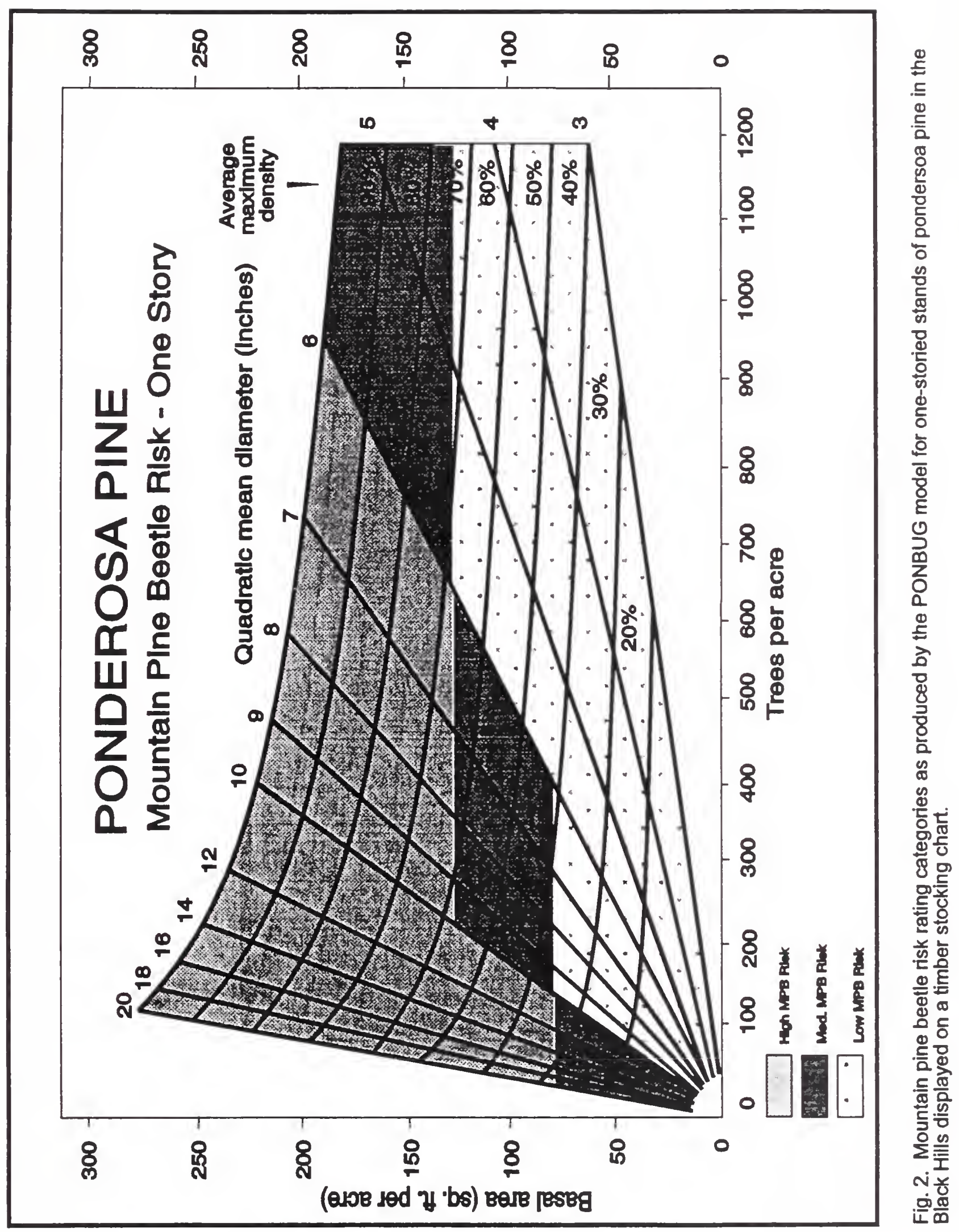





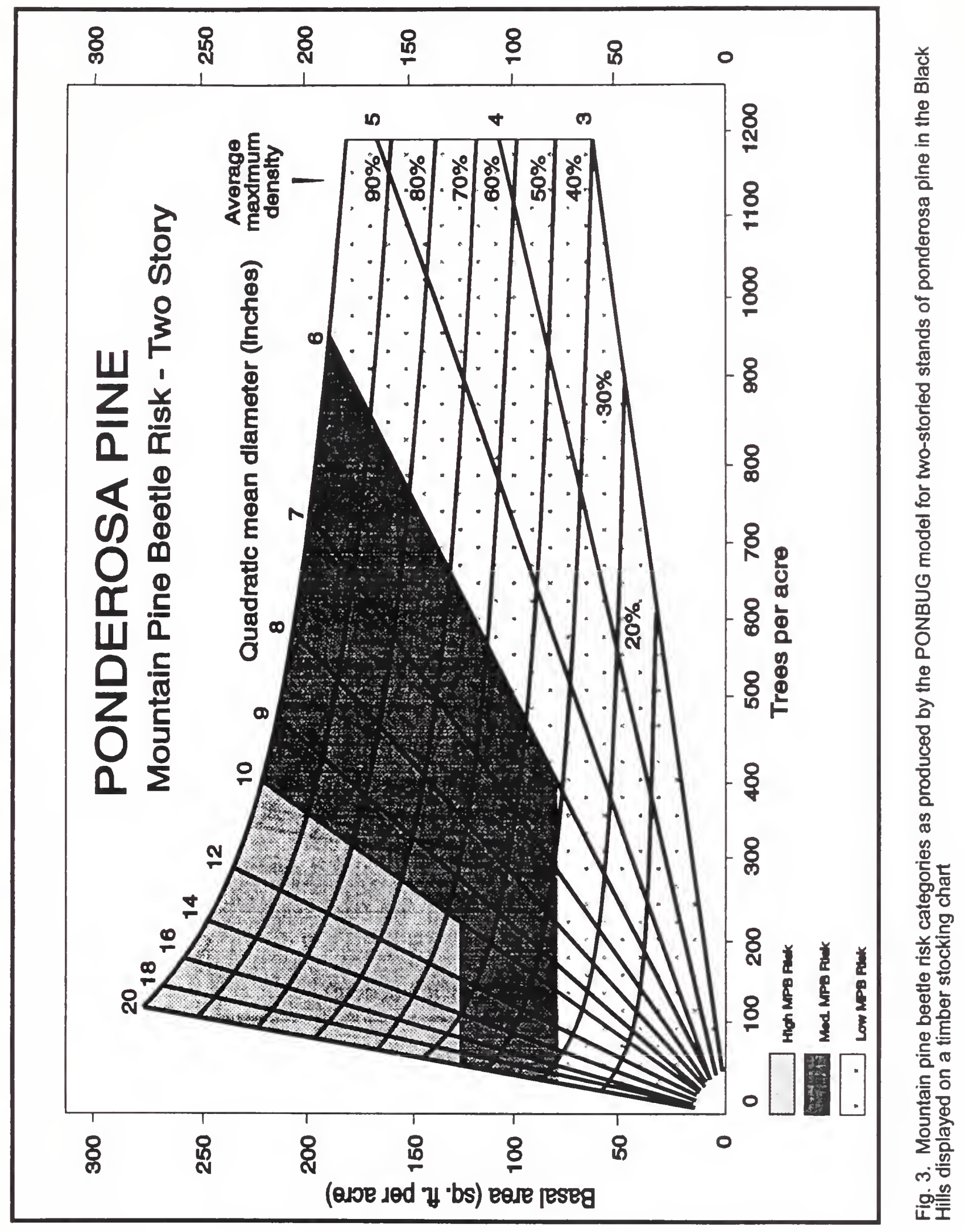




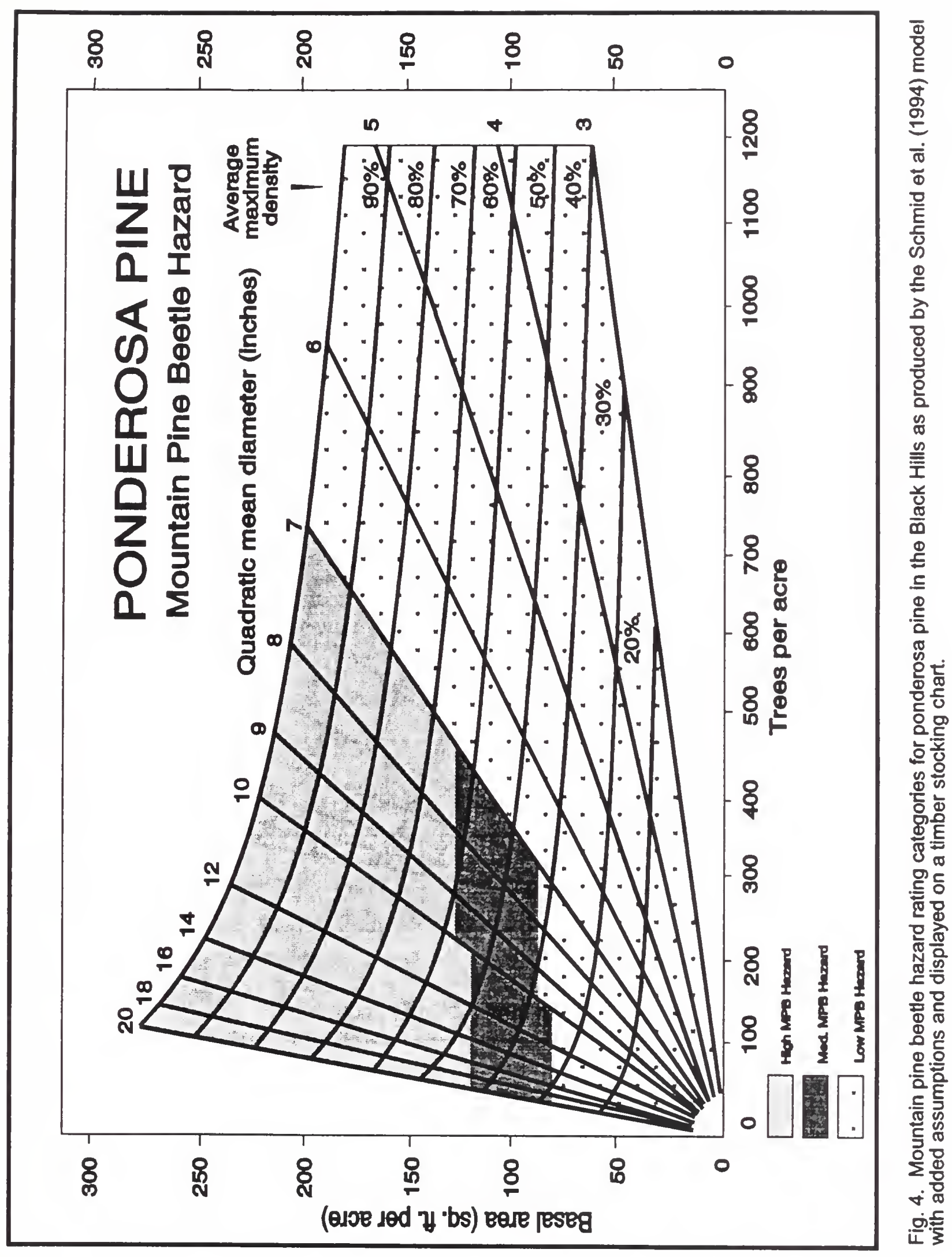



Table 3. Number and percent of ponderosa pine stands in each MPB risk/hazard rating category as determined by five calculation methods in four project areas.

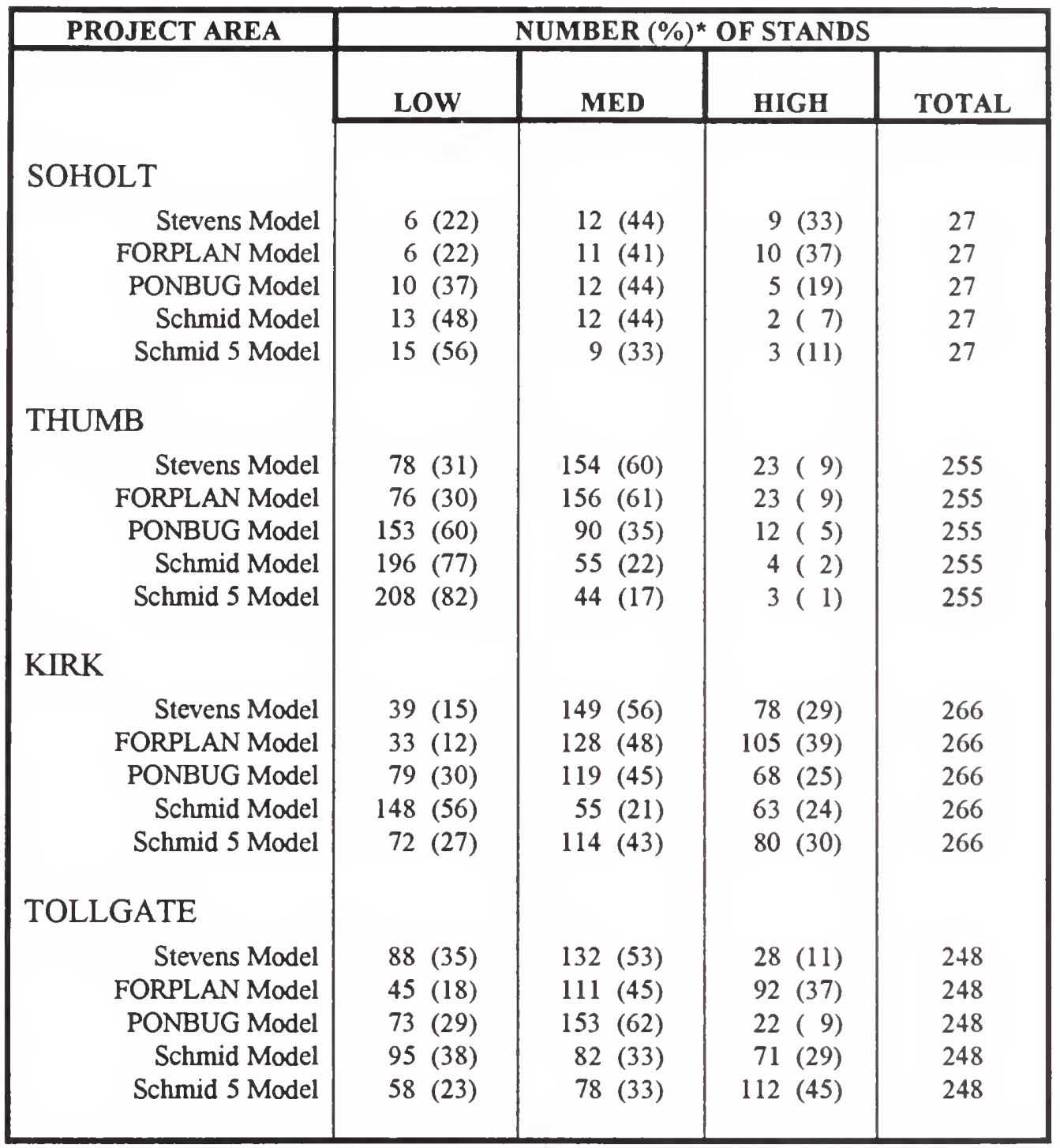

* Percentages of low, medium, and high may not total 100 due to rounding. 

Table 4. Number and percent of acres of ponderosa pine in each MPB risk/hazard rating category as determined by five calculation methods in four project areas.

\begin{tabular}{|c|c|c|c|c|}
\hline PROJECT AREA & & UMBER $(\%$ & OF ACRES & \\
\hline & LOW & MED & HIGH & TOTAL \\
\hline \multicolumn{5}{|l|}{ SOHOLT } \\
\hline Stevens Model & $331(15)$ & $1127(51)$ & $757(34)$ & 2215 \\
\hline FORPLAN Model & 331 (15) & $1078(49)$ & $806(36)$ & 2215 \\
\hline PONBUG Model & $928(42)$ & $988(45)$ & 299 (13) & 2215 \\
\hline Schmid Model & 1085 (49) & $1037(47)$ & $93(4)$ & 2215 \\
\hline Schmid 5 Model & $1382(62)$ & $706(32)$ & $127(6)$ & 2215 \\
\hline \multicolumn{5}{|l|}{ THUMB } \\
\hline Stevens Model & 4008 (29) & $8565(62)$ & 1305 ( 9) & 13878 \\
\hline FORPLAN Model & $3918(28)$ & $8655(62)$ & 1305 (9) & 13878 \\
\hline PONBUG Model & $8393(60)$ & $4806(35)$ & $679(5)$ & 13878 \\
\hline Schmid Model & $10518(76)$ & $3209(23)$ & $151(1)$ & 13878 \\
\hline Schmid 5 Model & $11082(80)$ & $2590(19)$ & $206(1)$ & 13878 \\
\hline \multicolumn{5}{|l|}{ KIRK } \\
\hline Stevens Model & $1625(16)$ & $5813(59)$ & 2481 & 9919 \\
\hline FORPLAN Model & $1402(14)$ & 5260 & 3257 & 9919 \\
\hline PONBUG Model & 3206 (32) & $4723(48)$ & $1990(20)$ & 9919 \\
\hline Schmid Model & $5627(57)$ & $2106(21)$ & $2186(22)$ & 9919 \\
\hline Schmid 5 Model & $2900(29)$ & $4567(46)$ & $2452(25)$ & 9919 \\
\hline \multicolumn{5}{|l|}{ TOLLGATE } \\
\hline Stevens Model & 4063 (45) & $4088(45)$ & 978 (11) & 9129 \\
\hline FORPLAN Model & $1894(21)$ & $4060(44)$ & $3175(35)$ & 9129 \\
\hline PONBUG Model & 3343 (37) & $5096(56)$ & $690(8)$ & 9129 \\
\hline Schmid Model & $3987(44)$ & $2899(32)$ & 2243 & 9129 \\
\hline Schmid 5 Model & $2273(25)$ & $3105(34)$ & $3751(41)$ & 9129 \\
\hline
\end{tabular}

* Percentages of low, medium, and high may not total 100 due to rounding. 

Table 5. Number of ponderosa pine stands changing rating category for mountain pine beetle risk/hazard between specified model pairs in four project areas.

\begin{tabular}{|c|c|c|c|c|c|c|c|c|}
\hline \multirow{3}{*}{$\begin{array}{l}\text { Project } \\
\text { Area }\end{array}$} & \multirow[t]{3}{*}{ Model Comparison } & \multicolumn{7}{|c|}{ Number of Stands Changing Risk/hazard Rating Category } \\
\hline & & \multicolumn{3}{|c|}{ Increase in Risk/hazard } & \multicolumn{3}{|c|}{ Decrease in Risk/hazard } & \multirow[b]{2}{*}{ No Change } \\
\hline & & $\begin{array}{l}\text { Low to } \\
\text { Medium }\end{array}$ & $\begin{array}{l}\text { Low } \\
\text { to } \\
\text { High }\end{array}$ & $\begin{array}{l}\text { Medium } \\
\text { to High }\end{array}$ & $\begin{array}{c}\text { Medium } \\
\text { to Low }\end{array}$ & $\begin{array}{l}\text { High to } \\
\text { Medium }\end{array}$ & $\begin{array}{l}\text { High } \\
\text { to Low }\end{array}$ & \\
\hline \multirow[t]{6}{*}{ Soholt } & Stevens to FORPLAN & 0 & 0 & 1 & 0 & 0 & 0 & 26 \\
\hline & Stevens to PONBUG & 1 & 0 & 1 & 5 & 5 & 0 & 15 \\
\hline & Stevens to Schmid & 3 & 0 & 1 & 9 & 7 & 1 & 6 \\
\hline & PONBUG to Schmid & 4 & 0 & 0 & 6 & 2 & 1 & 14 \\
\hline & Schmid to Schmid 5 & 2 & 1 & 0 & 5 & 0 & 0 & 19 \\
\hline & Stevens to Schmid 5 & 1 & 0 & 2 & 8 & 6 & 2 & 8 \\
\hline \multirow[t]{6}{*}{ Thumb } & Stevens to FORPLAN & 2 & 0 & 0 & 0 & 0 & 0 & 253 \\
\hline & Stevens to PONBUG & 4 & 0 & 0 & 79 & 11 & 0 & 161 \\
\hline & Stevens to Schmid & 14 & 0 & 1 & 131 & 19 & 1 & 89 \\
\hline & PONBUG to Schmid & 16 & 0 & 3 & 59 & 11 & 0 & 166 \\
\hline & Schmid to Schmid 5 & 2 & 2 & 0 & 16 & 3 & 0 & 232 \\
\hline & Stevens to Schmid 5 & 8 & 0 & 2 & 135 & 19 & 3 & 88 \\
\hline \multirow[t]{6}{*}{ Kirk } & Stevens to FORPLAN & 6 & 0 & 26 & 0 & 0 & 0 & 234 \\
\hline & Stevens to PONBUG & 2 & 0 & 5 & 43 & 15 & 0 & 201 \\
\hline & Stevens to Schmid & 3 & 0 & 16 & 103 & 22 & 9 & 113 \\
\hline & PONBUG to Schmid & 4 & 0 & 19 & 64 & 16 & 8 & 155 \\
\hline & Schmid to Schmid 5 & 48 & 33 & 0 & 5 & 17 & 0 & 163 \\
\hline & Stevens to Schmid 5 & 0 & 0 & 35 & 29 & 30 & 4 & 168 \\
\hline
\end{tabular}



Table 5 continued. Number of ponderosa pine stands changing rating category for mountain pine beetle risk/hazard between specified model pairs for four project areas.

\begin{tabular}{|c|c|c|c|c|c|c|c|c|}
\hline \multirow{3}{*}{$\begin{array}{l}\text { Project } \\
\text { Area }\end{array}$} & \multirow[t]{3}{*}{ Model Comparison } & \multicolumn{7}{|c|}{ Number of Stands Changing Risk/hazard Rating Category } \\
\hline & & \multicolumn{3}{|c|}{ Increase in Risk/hazard } & \multicolumn{3}{|c|}{ Decrease in Risk/hazard } & \multirow[b]{2}{*}{ No Change } \\
\hline & & $\begin{array}{l}\text { Low to } \\
\text { Medium }\end{array}$ & $\begin{array}{l}\text { Low } \\
\text { to } \\
\text { High }\end{array}$ & $\begin{array}{l}\text { Medium } \\
\text { to High }\end{array}$ & $\begin{array}{c}\text { Medium } \\
\text { to Low }\end{array}$ & $\begin{array}{l}\text { High to } \\
\text { Medium }\end{array}$ & $\begin{array}{l}\text { High } \\
\text { to Low }\end{array}$ & \\
\hline \multirow[t]{6}{*}{ Tollgate } & Stevens to FORPLAN & 43 & 0 & 64 & 0 & $\overline{0}$ & 0 & 141 \\
\hline & Stevens to PONBUG & 21 & 0 & 6 & 5 & 11 & 1 & 204 \\
\hline & Stevens to Schmid & 21 & 0 & 48 & 27 & 4 & 1 & 147 \\
\hline & PONBUG to Schmid & 5 & 0 & 52 & 27 & 3 & 0 & 161 \\
\hline & Schmid to Schmid 5 & 29 & 19 & 31 & 11 & 9 & 0 & 149 \\
\hline & Stevens to Schmid 5 & 22 & 13 & 75 & 5 & 4 & 0 & 129 \\
\hline \multirow[t]{6}{*}{ All } & Stevens to FORPLAN & 51 & 0 & 91 & 0 & 0 & 0 & 654 \\
\hline & Stevens to PONBUG & 28 & 0 & 12 & 132 & 42 & 1 & 581 \\
\hline & Stevens to Schmid & 41 & 0 & 66 & 270 & 52 & 12 & 355 \\
\hline & PONBUG to Schmid & 29 & 0 & 74 & 156 & 32 & 9 & 496 \\
\hline & Schmid to Schmid 5 & 81 & 55 & 31 & 37 & 29 & 0 & 563 \\
\hline & Stevens to Schmid 5 & 31 & 13 & 114 & 177 & 59 & 9 & 393 \\
\hline
\end{tabular}



PONBUG model rather than using comparable data based upon trees $\geq 5$ inches DBH. Including trees of smaller (1 - 4.9 inch) DBH in the data would tend to reduce mean diameter or QMD and increase BA values used in MPB risk/hazard rating calculations. The pattern of change in stand ratings likely was different for the Tollgate project compared to the other locations due to very high numbers of small trees in many stands. Trees per acre in the $1-4.9$ inch diameter class averaged 1,781 per stand for the Tollgate project compared to 92, 58, and 219 for the Soholt, Thumb, and Kirk projects, respectively. For the Soholt, Thumb, and Kirk projects, the differences in MPB risk/hazard rating for these two methods likely were due primarily to lower $\mathrm{QMD}$ _1 values relative to $\mathrm{QMD} 5$ values. For the Tollgate project, there likely was a more complex mix of lower $\mathrm{QMD}$ _1 values and higher BA_1 values that affected results of the PONBUG model compared to the QMD_5 and BA_5 values used by the Stevens model.

The Schmid model tended to shift even more stands and acres to the low MPB risk/hazard category than the PONBUG model did relative to the Stevens model (Tables 3-4). In general, stands and acres in the medium and high MPB risk/hazard categories declined for the Schmid model relative to the Stevens, FORPLAN, and PONBUG models, with a few exceptions, most notably the high MPB risk/hazard category in the Tollgate project (Tables $3-4$ ). Most stands that changed ratings in the Schmid model compared to the Stevens and PONBUG models went from the medium to low risk/hazard categories in the Soholt, Thumb and Kirk projects, but from medium to high MPB risk/hazard in the Tollgate project (Table 5). The Schmid model shifted MPB risk/hazard ratings relative to the PONBUG model as would generally be expected from examination of the stocking charts in Figs. 2-4, given a representative array of stand conditions. This suggests that the stands in the four project areas analyzed in this report provided a reasonable variety of stand conditions. The variation in direction of change (increase or decrease) for the Schmid model relative to the PONBUG and Stevens models for the high MPB risk/hazard category for different project areas likely reflects the absence of stand structure as a model component in the Schmid model. The high numbers of small ( $1-4.9$ inch DBH) trees in the Tollgate project resulted in $86 \%$ of the stands being classified as two-storied in the Stevens and PONBUG models compared to 7, 2, and 18 percent, respectively, for the Soholt, Thumb, and Kirk projects. A preponderance of one-storied stands (as found in the Soholt, Thumb, and Kirk projects) might tend to produce fewer stands with high MPB risk/hazard ratings as compared to a method such as the Schmid model that considers only average tree diameters and densities. Although Schmid et al. (1994) did not specify a minimum tree diameter to be used in model calculations, their method was based upon data from stands that contained few trees $<4$ inches DBH. The method is geared toward even-aged stands where most trees are of susceptible size. Therefore, the Schmid model may not adequately reflect MPB risk/hazard levels for uneven-aged stands and those with many trees of small DBH. The assumption added to classify stands with QMD $<7$ inches as being low risk/hazard may also lead to more low ratings than might be reasonably expected. For example, a stand of high basal area with trees in the $4-10$ inch DBH classes might have a QMD just below 7 inches and yet have many suitable host trees for MPB infestation. Interestingly, the Schmid model tends to provide more conservative estimates of MPB risk/hazard in ponderosa pine than the Stevens model and its variations.

No consistent pattern was found in how risk/hazard ratings changed if small trees ( $<5$ inches) were ignored, as in the Schmid 5 model (Tables 3-5). The Schmid 5 model tended to shift more stands and acres into the low MPB risk/hazard category for the Soholt and Thumb project areas, but more into the high MPB risk/hazard category for the Tollgate project relative to the other four methods (Tables 3-4). For the Kirk project, ratings produced by the Schmid 5 model tended to be intermediate compared to the other models (Tables 3-4). For the Soholt and Thumb projects, the greatest change was from medium to low MPB risk/hazard when comparing both the Stevens and Schmid models to the Schmid 5 model (Table 5). For the Tollgate project, substantially more stands increased in MPB risk/hazard rating than decreased for the same model comparisons, with the greatest change being from medium to high MPB risk/hazard (Table 5). In the Kirk project, the greatest change from the Schmid model to the Schmid 5 model was from low to medium MPB risk/hazard, while many stands also went from low to high MPB risk/hazard (Table 5). In contrast, the greatest change from the Stevens model to the Schmid 5 model in the Kirk project was from medium to high MPB risk/hazard; however, more stands decreased in MPB risk/hazard than increased overall (Table 5). There appears to be little relationship between which stands rated high for the Schmid 5 model relative to the other methods (Figs. 5-24). The lack of correspondence 

between stand risk/hazard ratings for the Schmid 5 model relative to the Stevens model suggests that there are inherent differences in the way the Stevens and Schmid models calculate MPB risk/hazard that are independent of which data parameters for QMD and BA were used.

Unfortunately, the analyses of model differences presented in this report cannot differentiate which is closest to correct as related to MPB behavior in field settings. Such a determination requires waiting for natural outbreaks of MPB populations in Black Hills ponderosa pine stands where damage levels can be compared to stand risk/hazard levels predicted by the various models.

The Schmid model was used for analysis of effects of management alternatives in the Final EIS for the 1997 Revision of the Land and Resource Management Plan of the Black Hill National Forest, rather than the FORPLAN model that was used in the Draft EIS. This decision was made based upon the currency of the research and because the method was developed from data obtained from stands exposed to MPB infestation rather than being derived mostly from general observations. As long as the same method was applied to all alternatives considered in the plan, the relative ranking of alternatives should be valid, within the limits of our knowledge, even if the actual magnitude of acres ranked as low, medium, and high are not entirely accurate. The PONBUG model has continued to be used by district staffs for conducting environmental analyses of proposed project areas on the Black Hills National Forest. Consideration should be given to correcting the PONBUG model to match criteria developed by Stevens et al. (1980) or to switching from the use of the PONBUG model to the Schmid model for project-level planning, depending on which of the models appears to better reflect MPB infestations in the Black Hills in the future. Further refinement of either of these models is also needed, especially as management of the ponderosa pine type shifts from application of predominately even-aged silvicultural systems with even tree spacing to greater emphasis on variable density thinning and possibly uneven-aged harvesting to enhance structural diversity and visual objectives. 



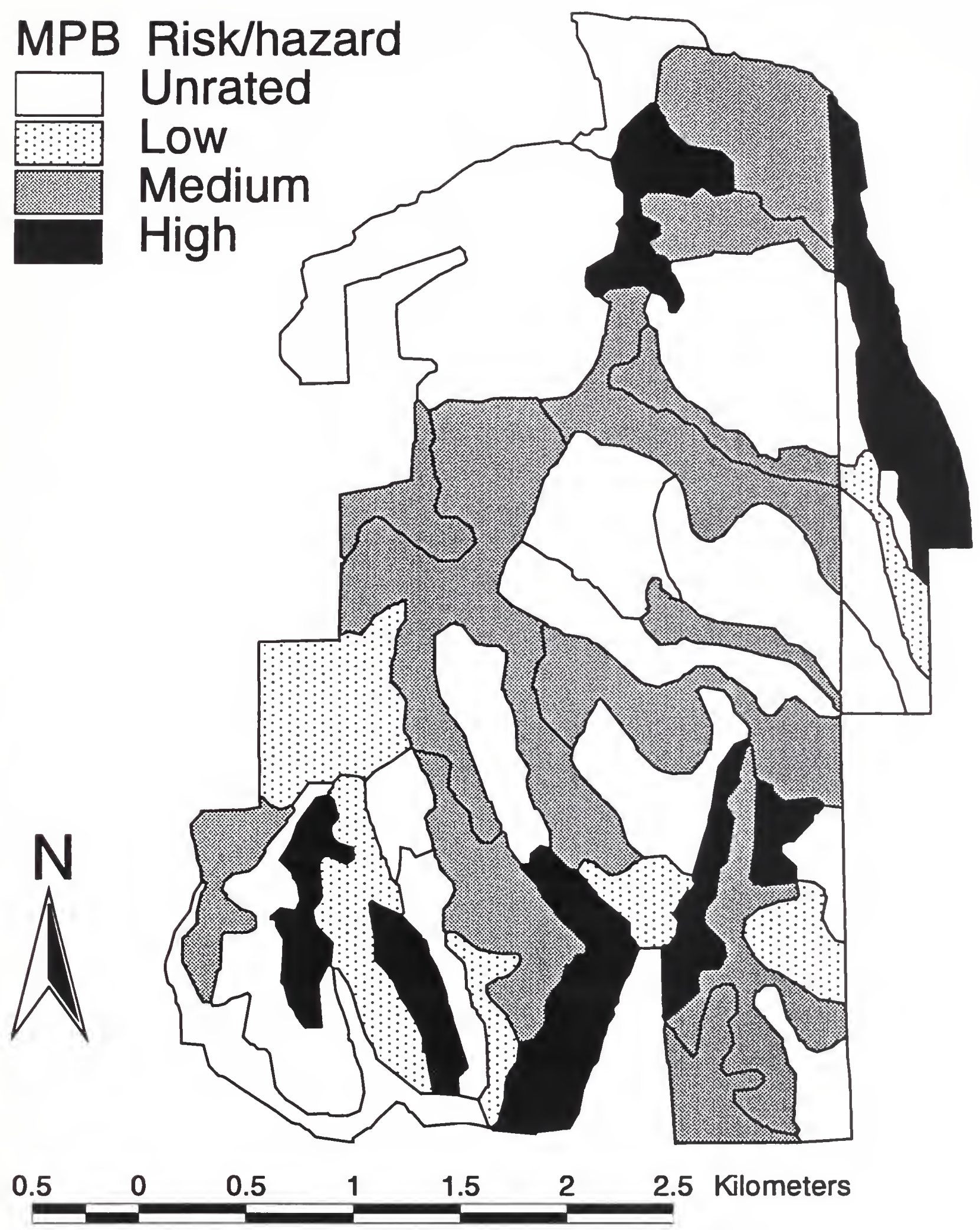

Fig. 5. Mountain pine beetle risk/hazard ratings displayed on geographic information system (GIS) maps as generated by the Stevens model for the Soholt project area. 



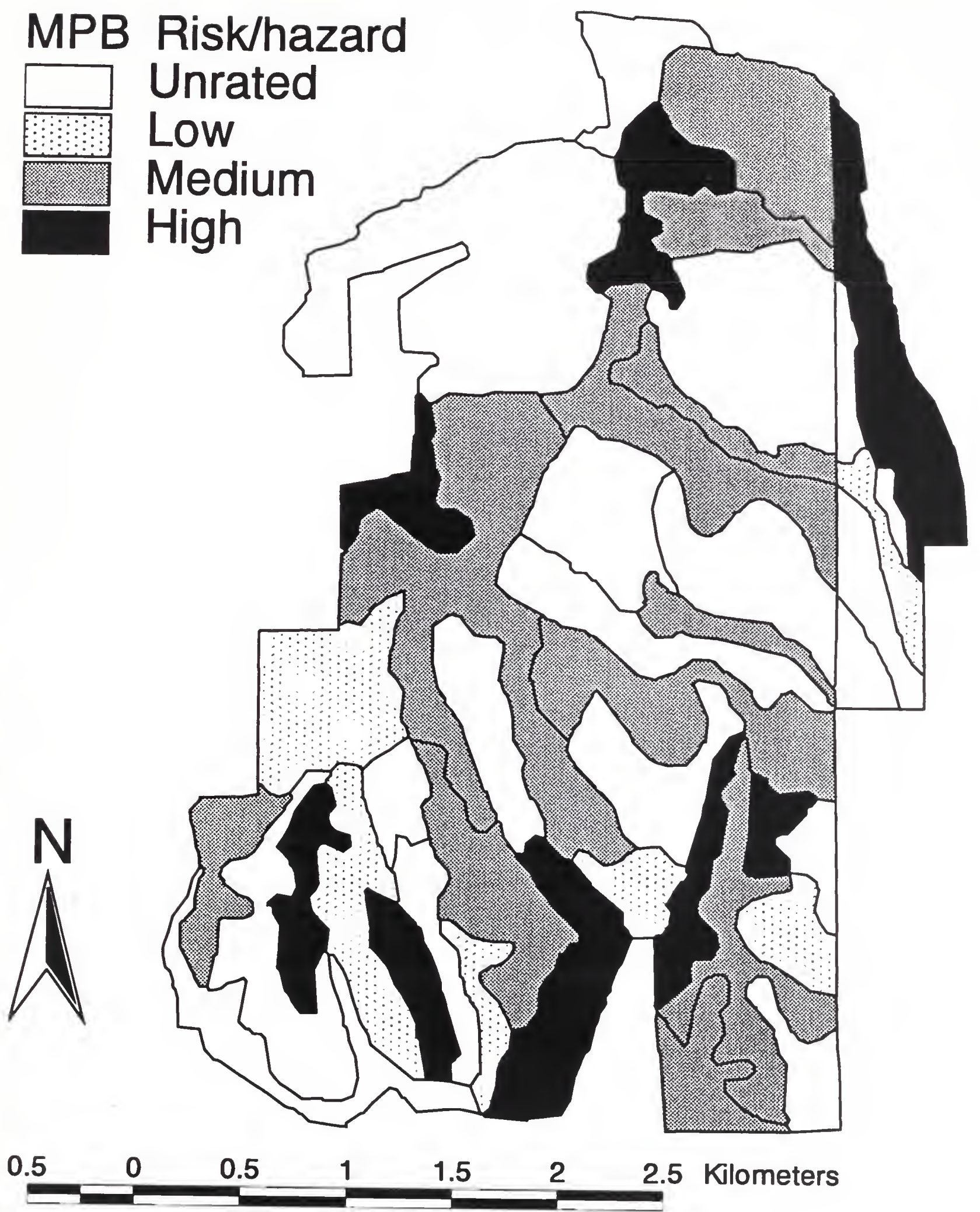

Fig. 6. Mountain pine beetle risk/hazard ratings displayed on geographic information system (GIS) maps as generated by the FORPLAN model for the Soholt project area. 



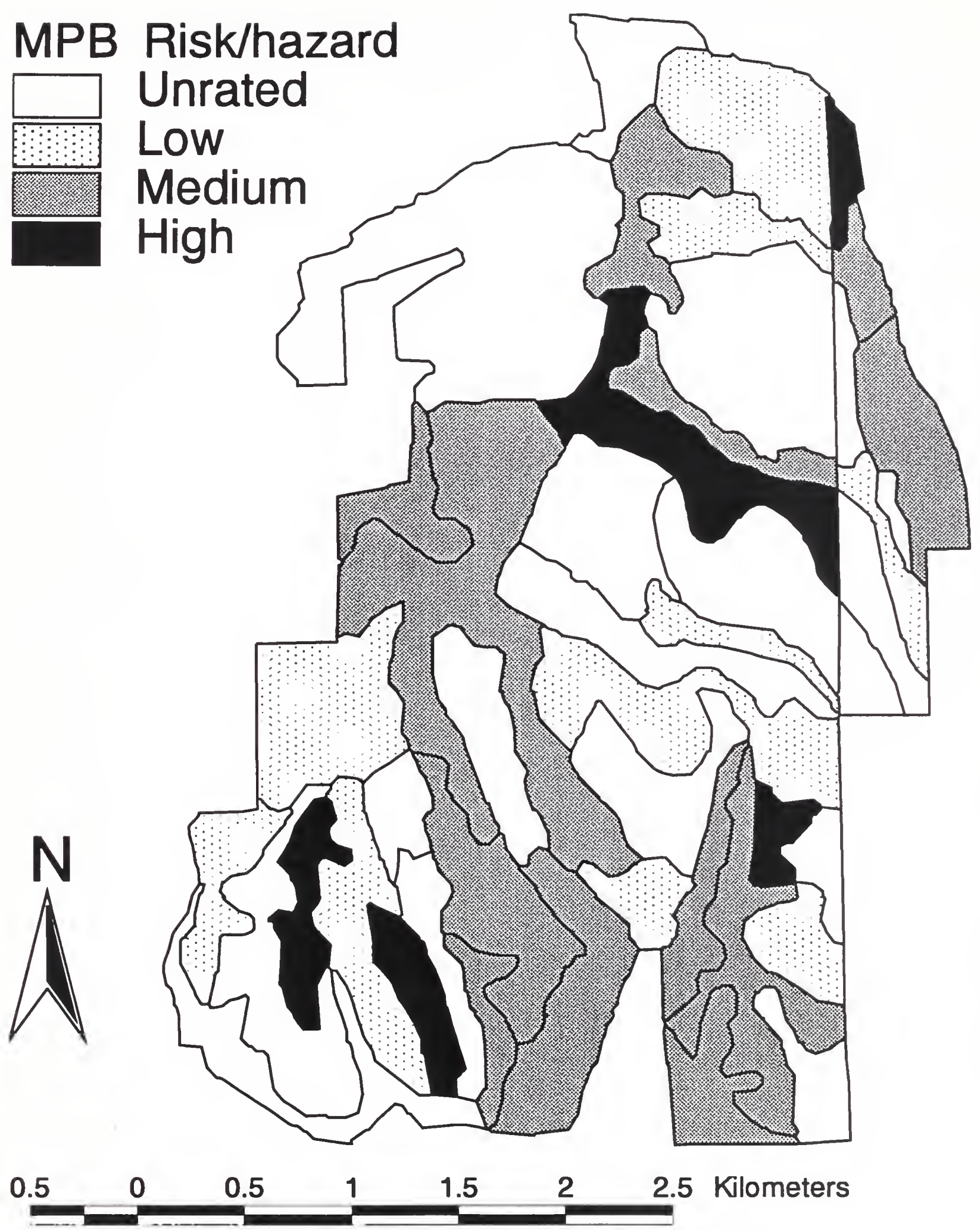

Fig. 7. Mountain pine beetle risk/hazard ratings displayed on geographic information system (GIS) maps as generated by the PONBUG model for the Soholt project area. 



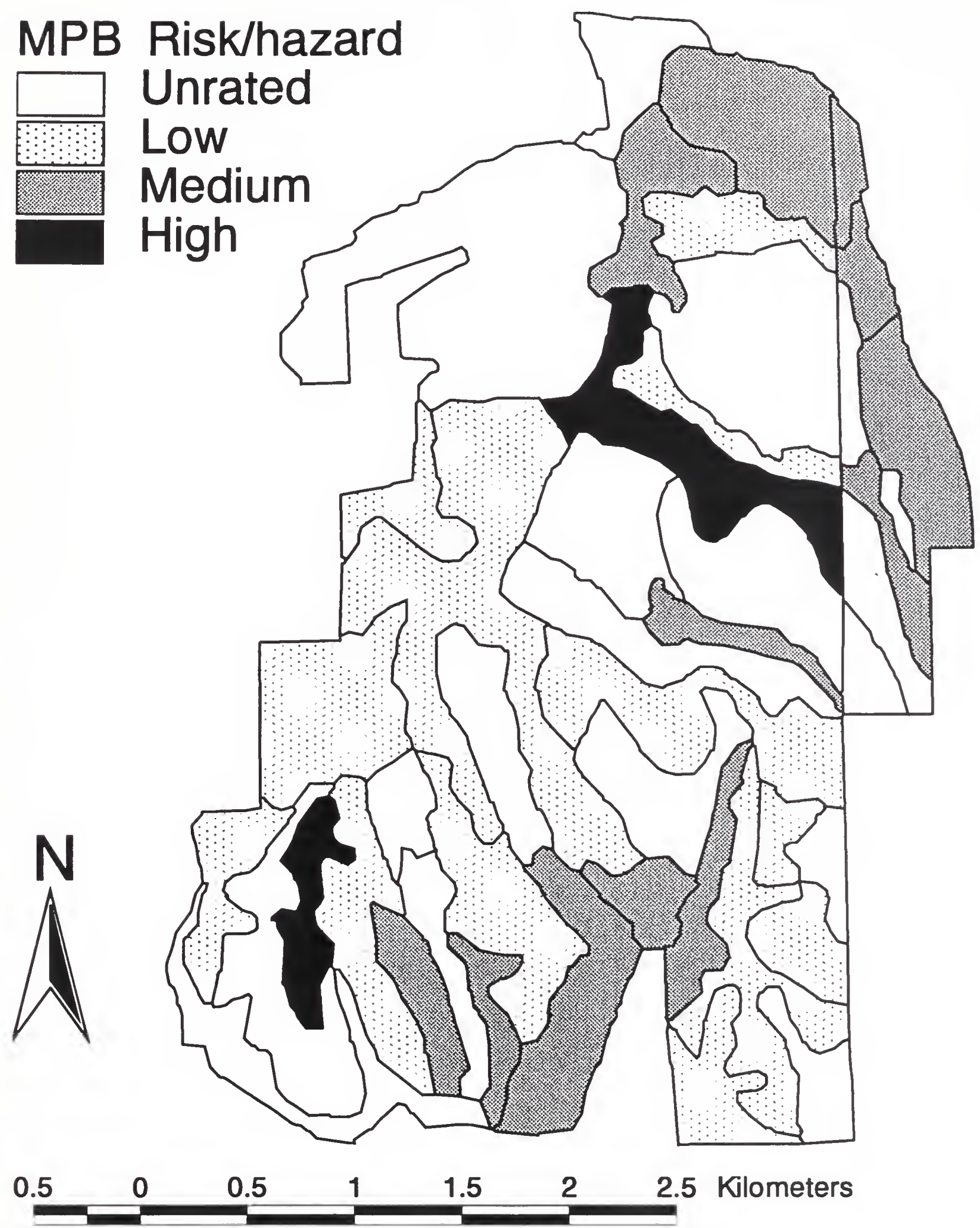

Fig. 8. Mountain pine beetle risk/hazard ratings displayed on geographic information system (GIS) maps as generated by the Schmid model for the Soholt project area. 



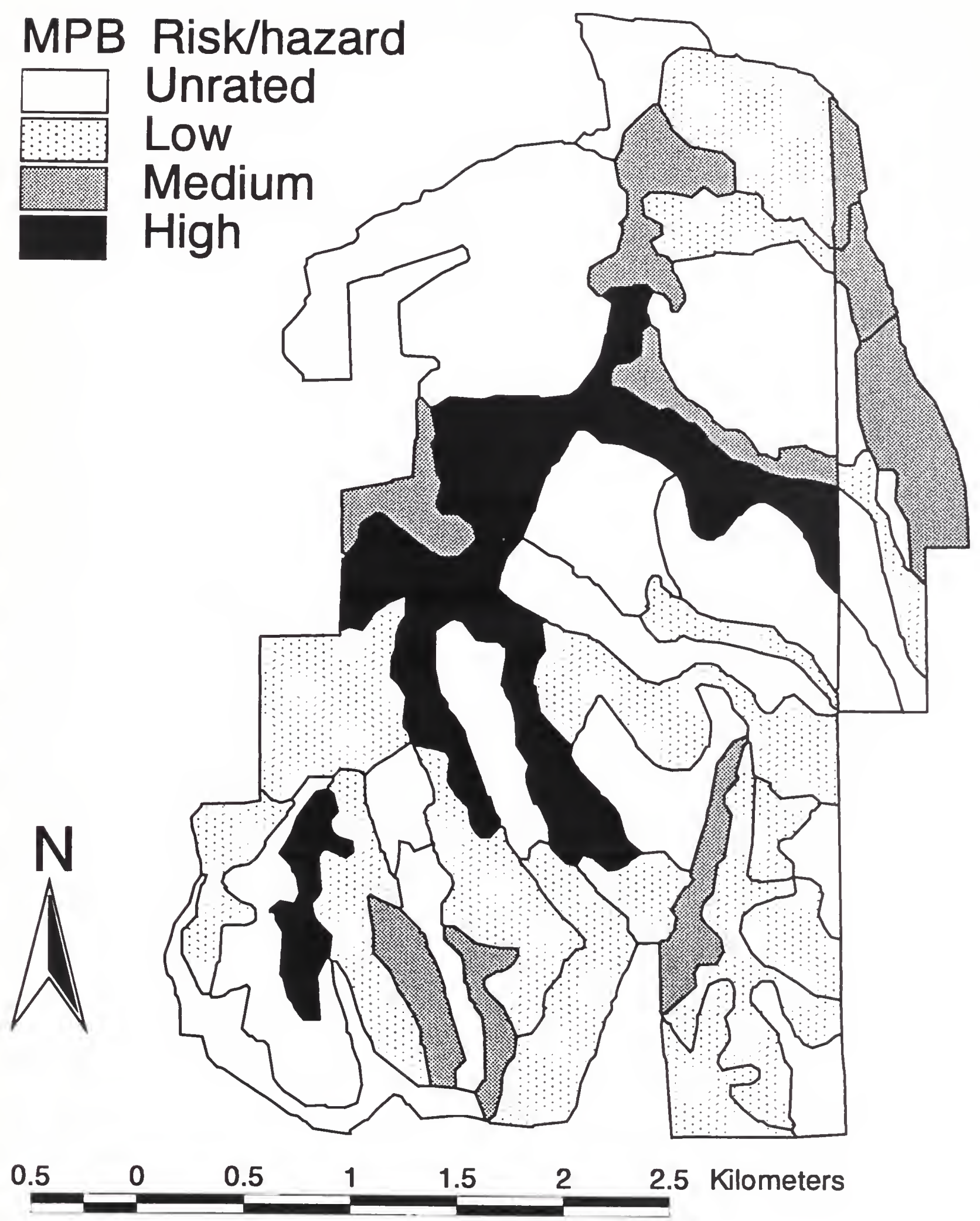

Fig. 9. Mountain pine beetle risk/hazard ratings displayed on geographic information system (GIS) maps as generated by the Schmid 5 model for the Soholt project area. 



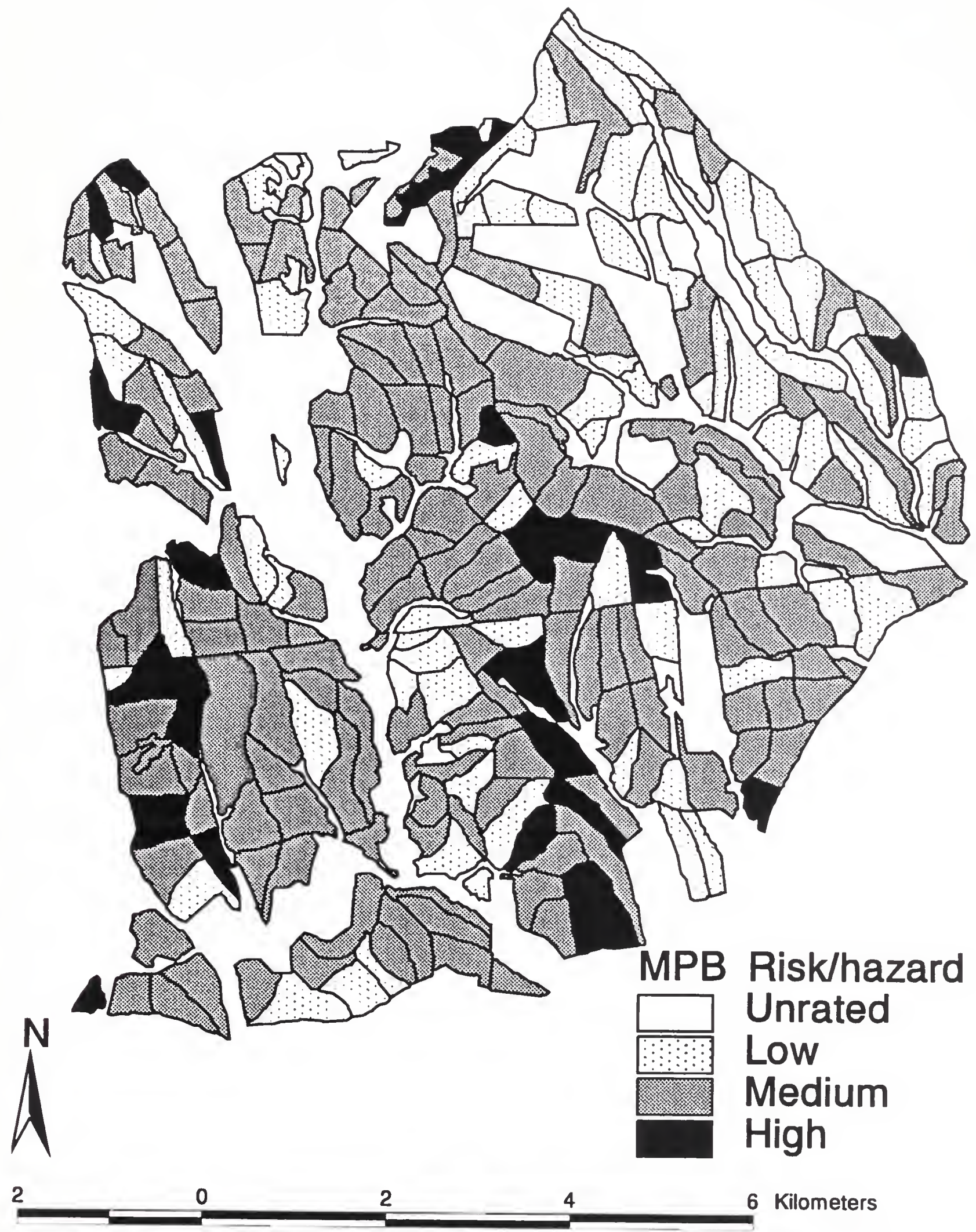

Fig. 10. Mountain pine beetle risk/hazard ratings displayed on geographic information system (GIS) maps as generated by the Stevens model for the Thumb project area. 



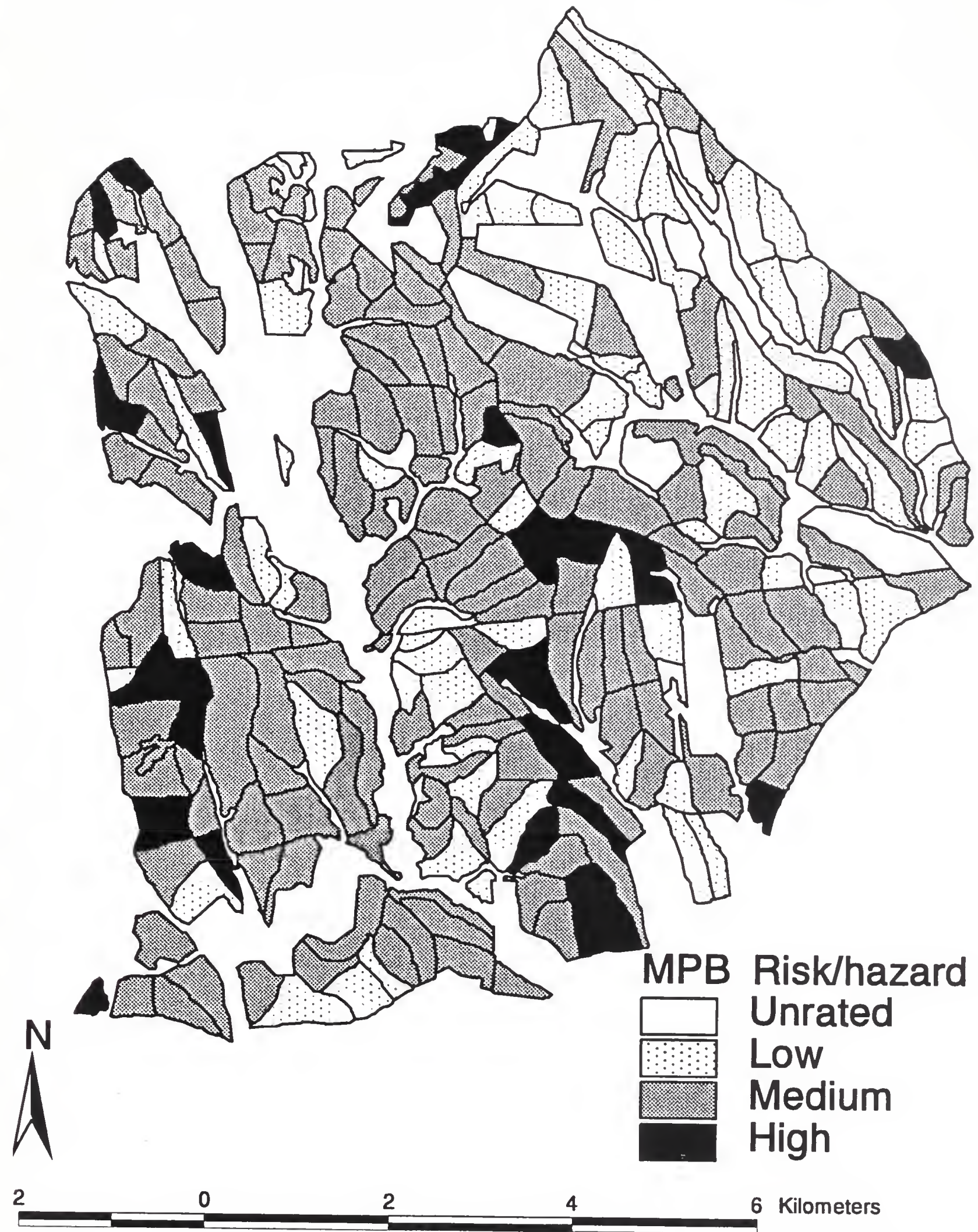

Fig. 11. Mountain pine beetle risk/hazard ratings displayed on geographic information system (GIS) maps as generated by the FORPLAN model for the Thumb project area. 



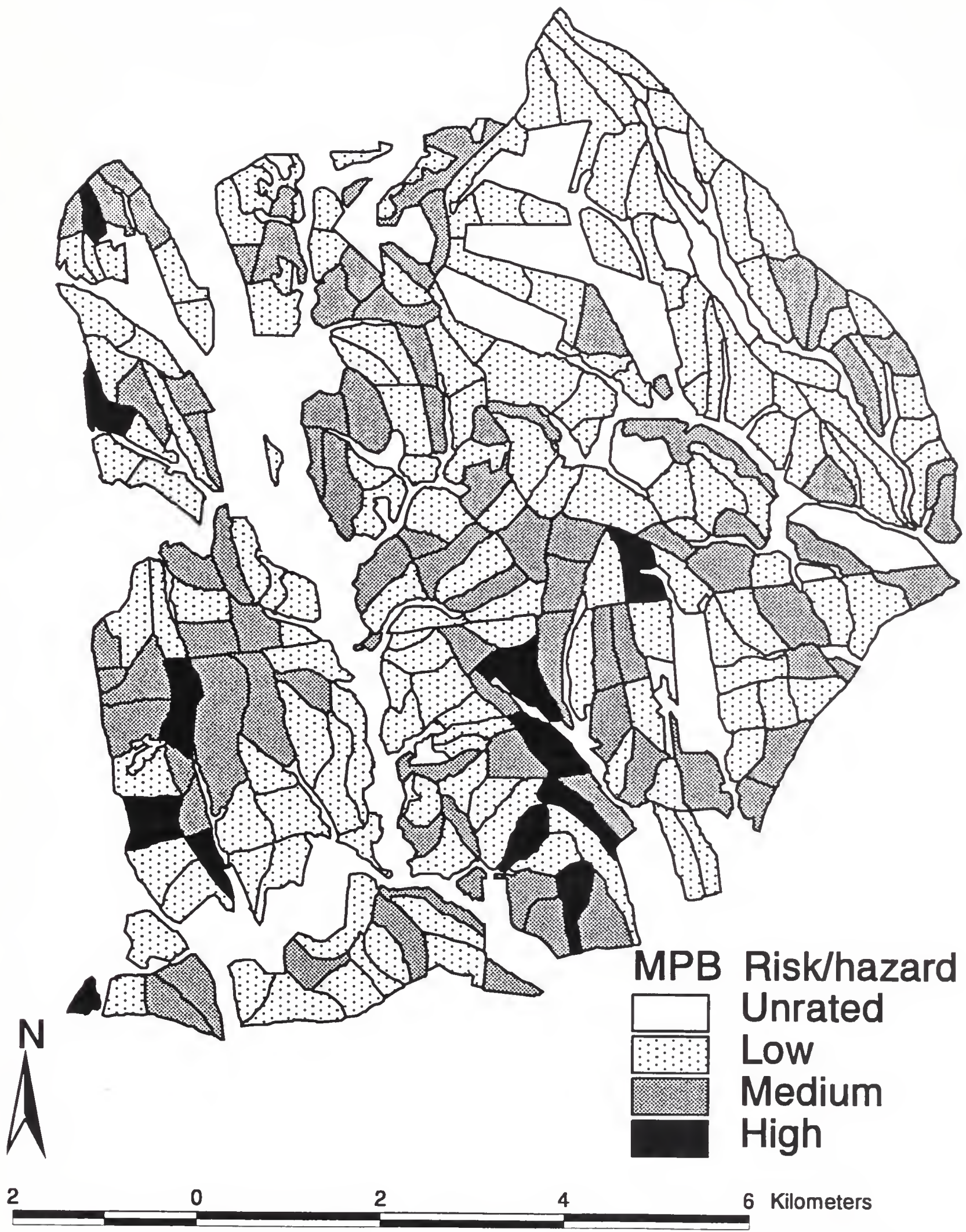

Fig. 12. Mountain pine beetle risk/hazard ratings displayed on geographic information system (GIS) maps as generated by the PONBUG model for the Thumb project area. 



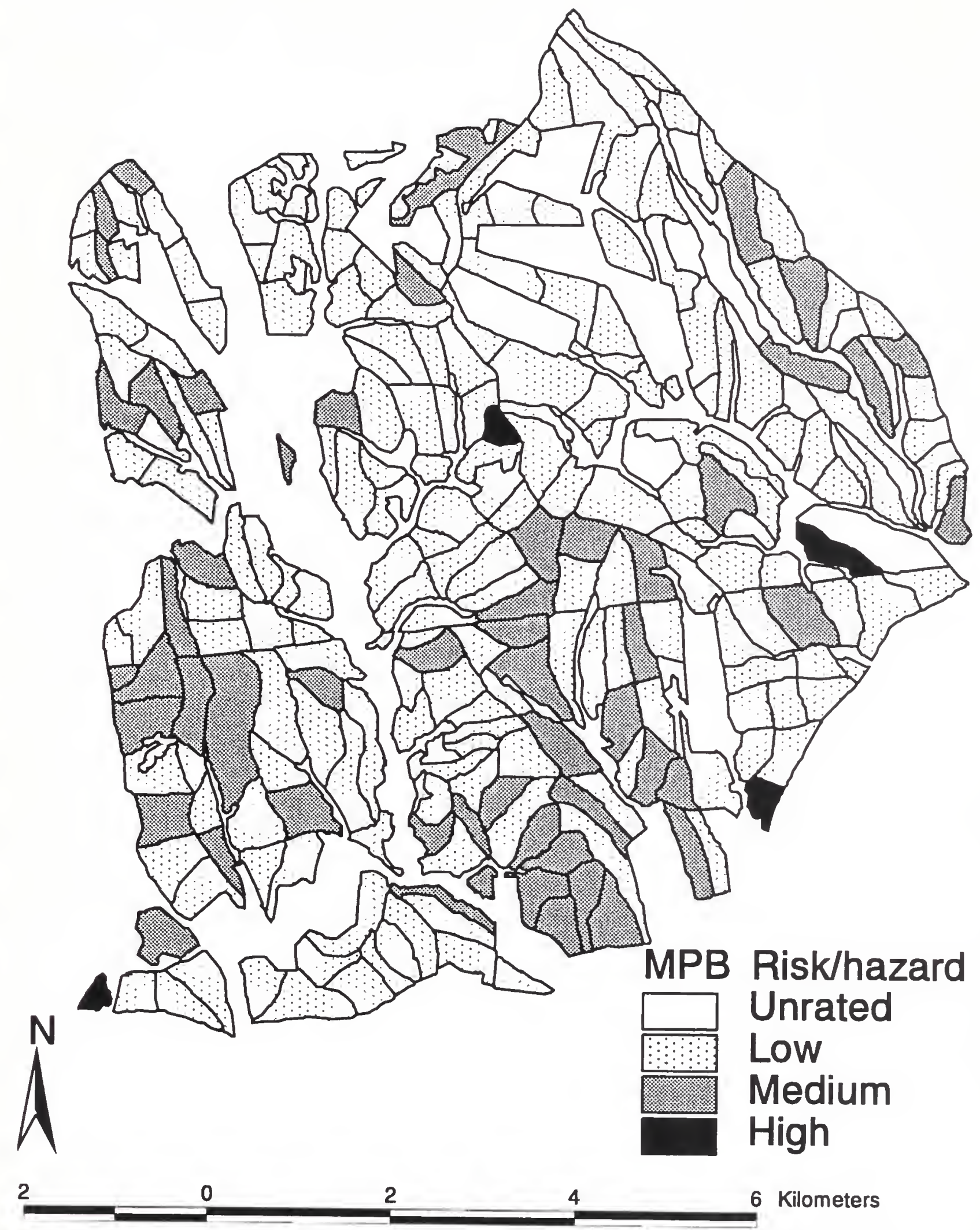

Fig. 13. Mountain pine beetle risk/hazard ratings displayed on geographic information system (GIS) maps as generated by the Schmid model for the Thumb project area. 



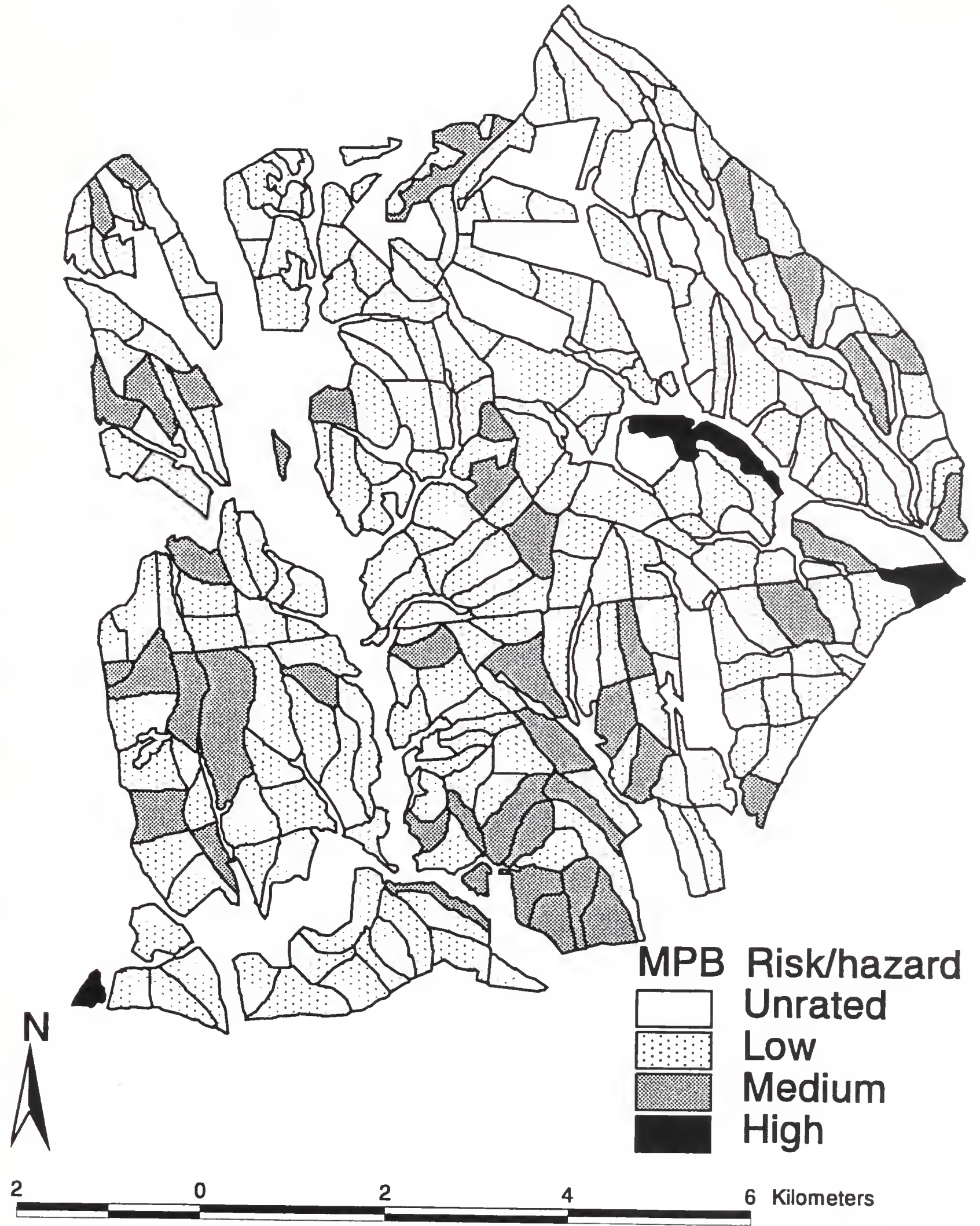

Fig. 14. Mountain pine beetle risk/hazard ratings displayed on geographic information system (GIS) maps as generated by the Schmid 5 model for the Thumb project area. 



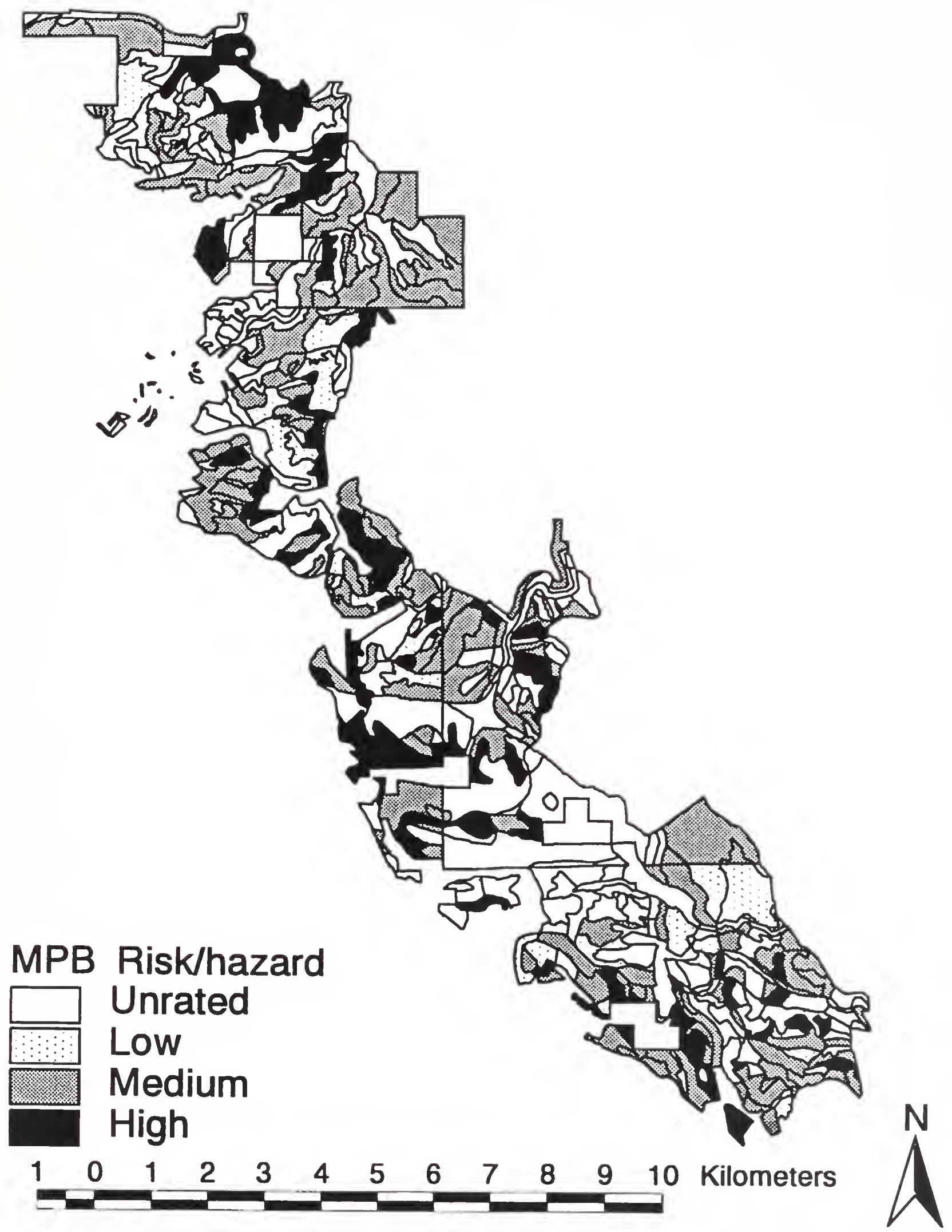

Fig. 15. Mountain pine beetle risk/hazard ratings displayed on geographic information systen: (GIS) maps as generated by the Stevens model for the Kirk project area. 



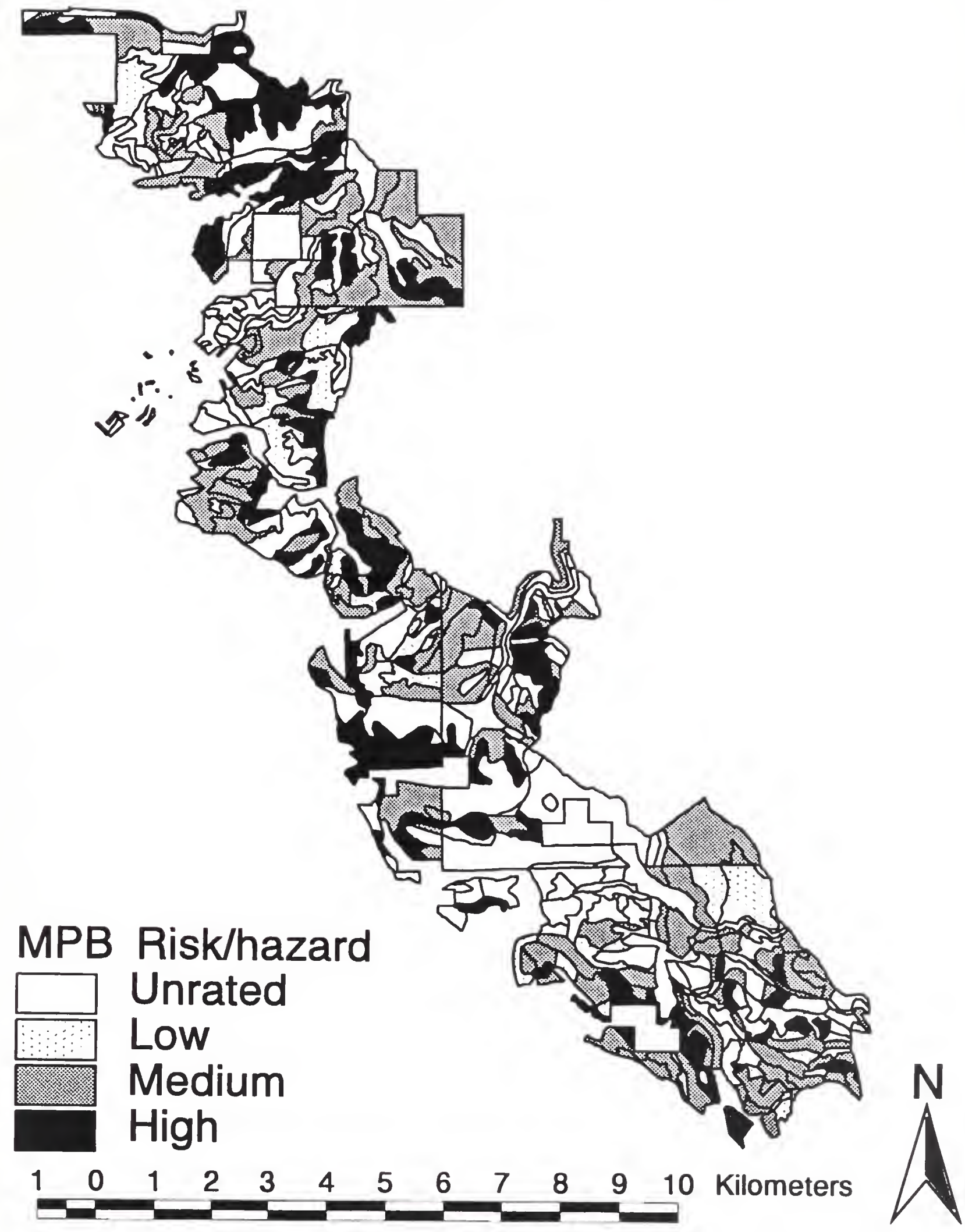

Fig. 16. Mountain pine beetle risk/hazard ratings displayed on geographic information system ((jIS) maps as generated by the FORPLAN model for the Kirk project area. 



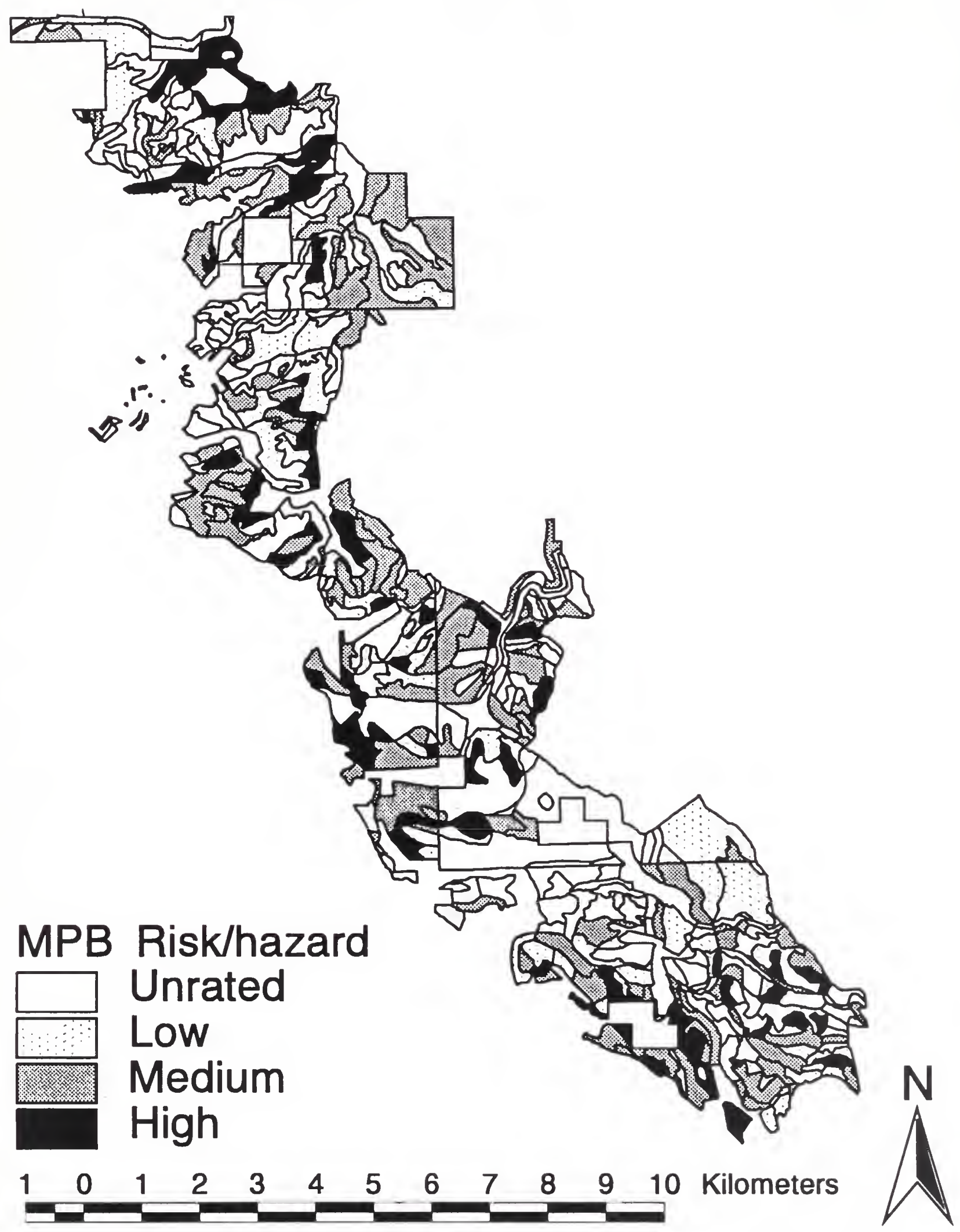

Fig. 17. Mountain pine beetle risk/hazard ratings displayed on geographic information system (GIS) maps as generated by the PONBUG model for the Kirk project area. 



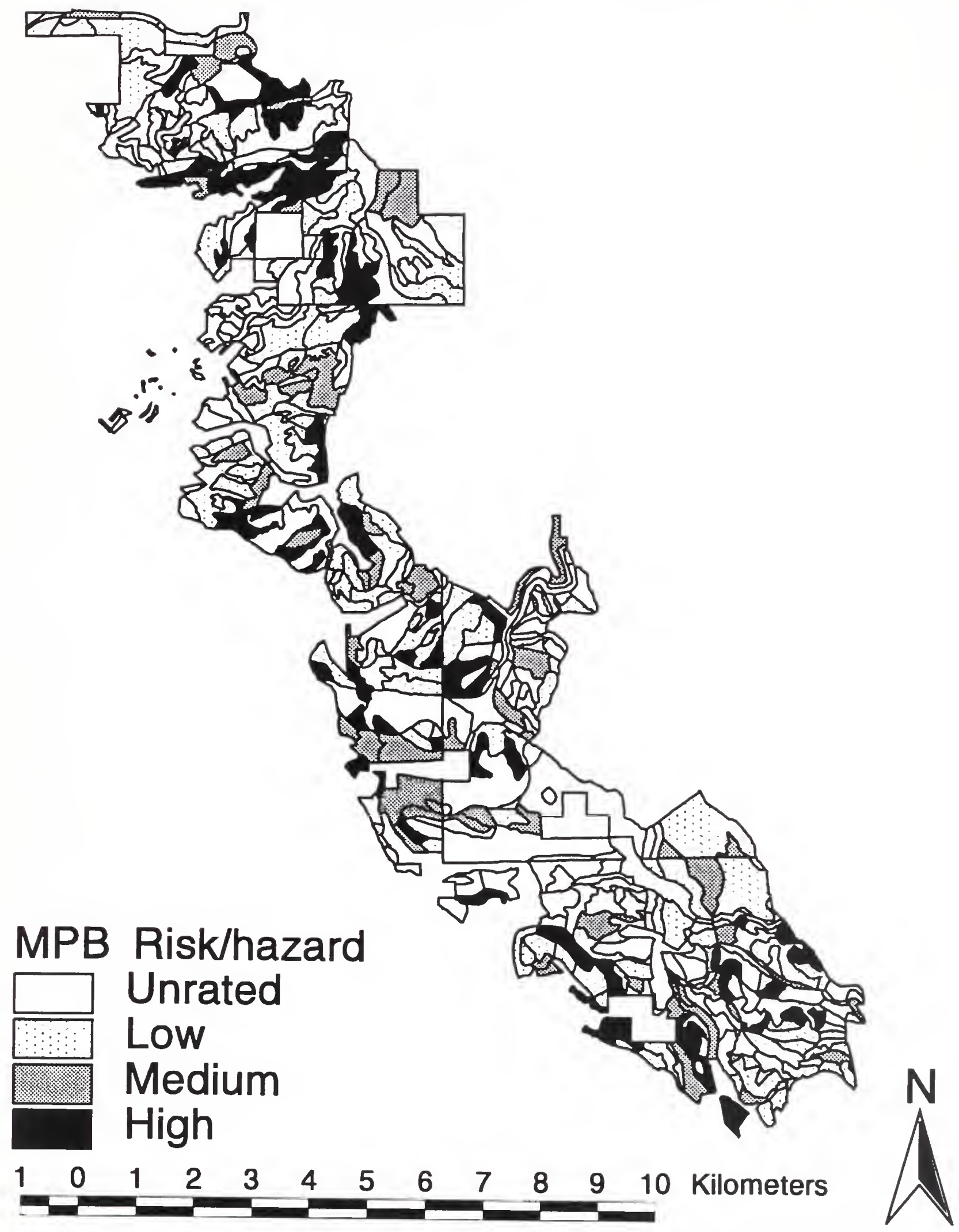

Fig. 18. Mountain pine beetle risk/hazard ratings displayed on geographic information system (GIS) maps as generated by the Schmid model for the Kirk project area. 



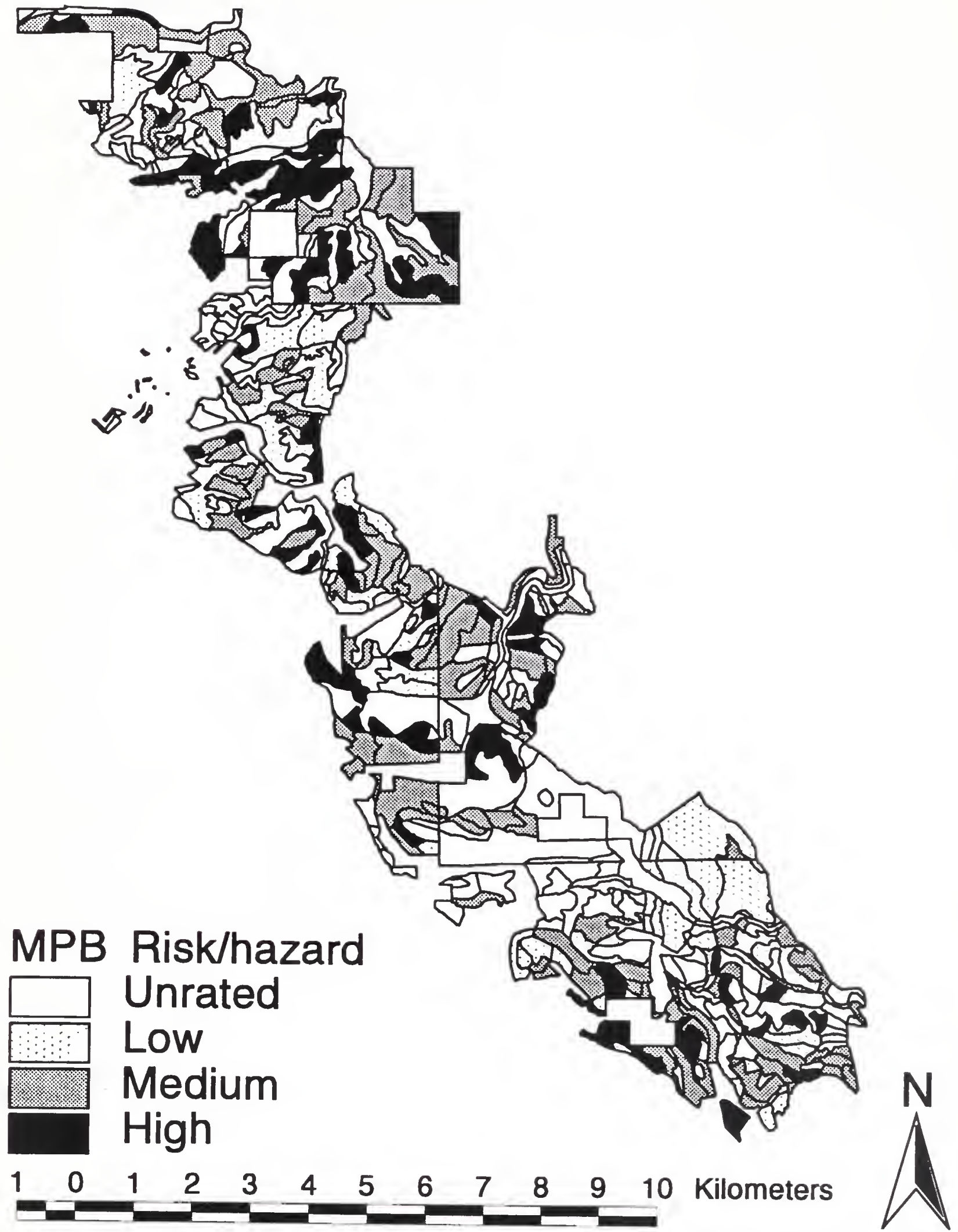

Fig. 19. Mountain pine beetle risk/hazard ratings displayed on geographic information system (GIS) maps as generated by the Schmid 5 model for the Kirk project area. 



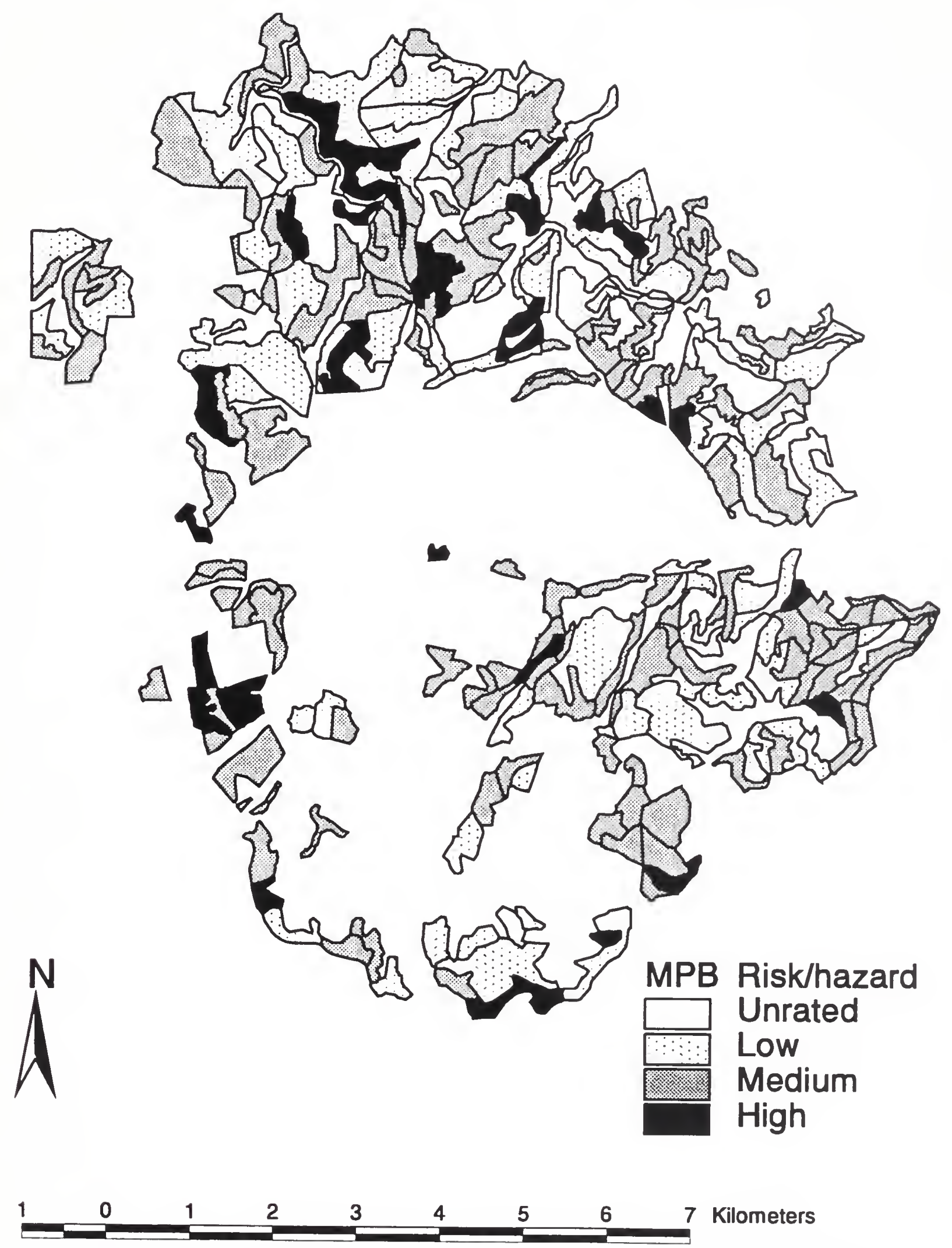

Fig. 20. Mountain pine beetle risk/hazard ratings displayed on geographic information system (GIS) maps as generated by the Stevens model for the Tollgate project area. 



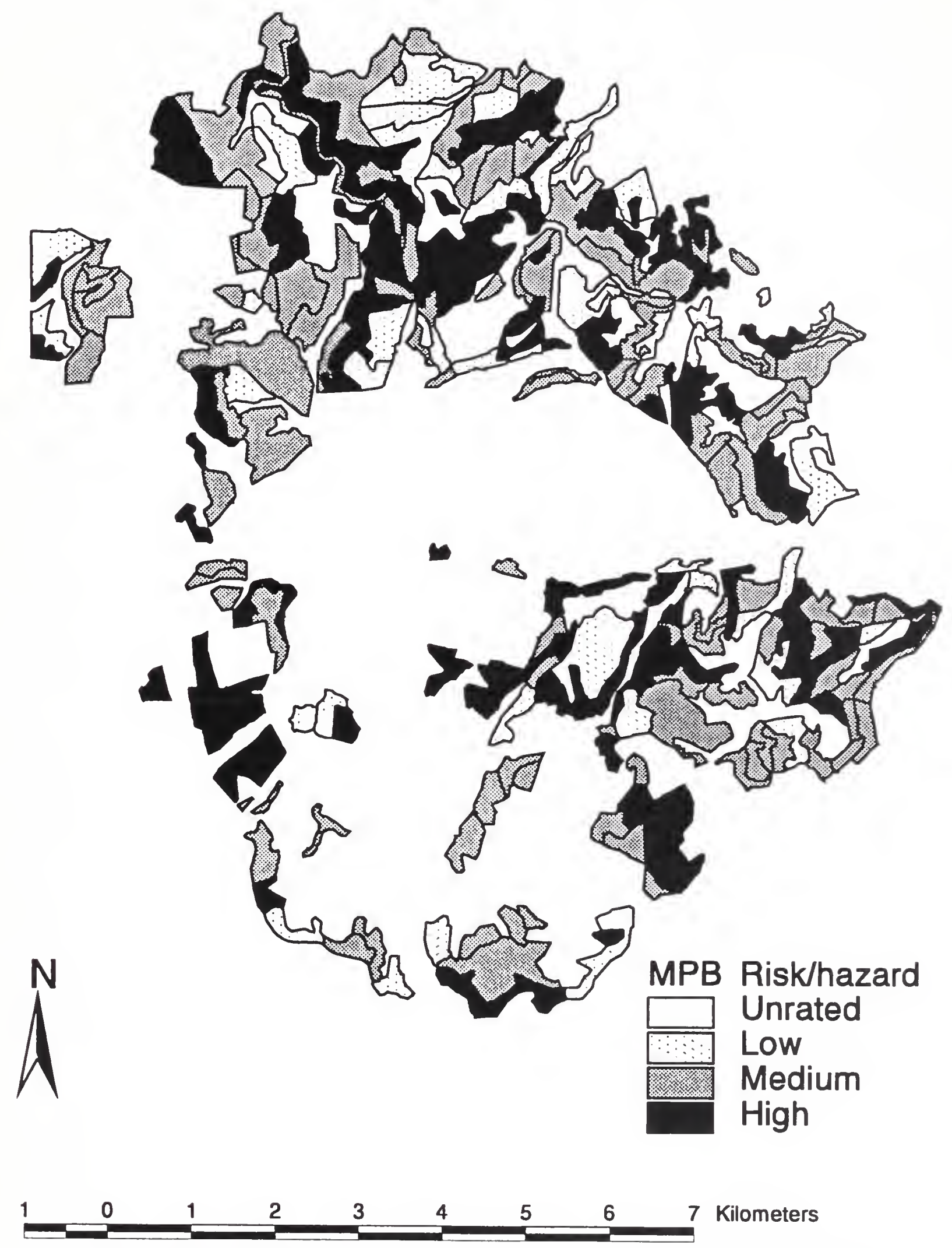

Fig. 21. Mountain pine beetle risk/hazard ratings displayed on geographic information system (GIS) maps as generated by the FORPLAN model for the Tollgate project area. 



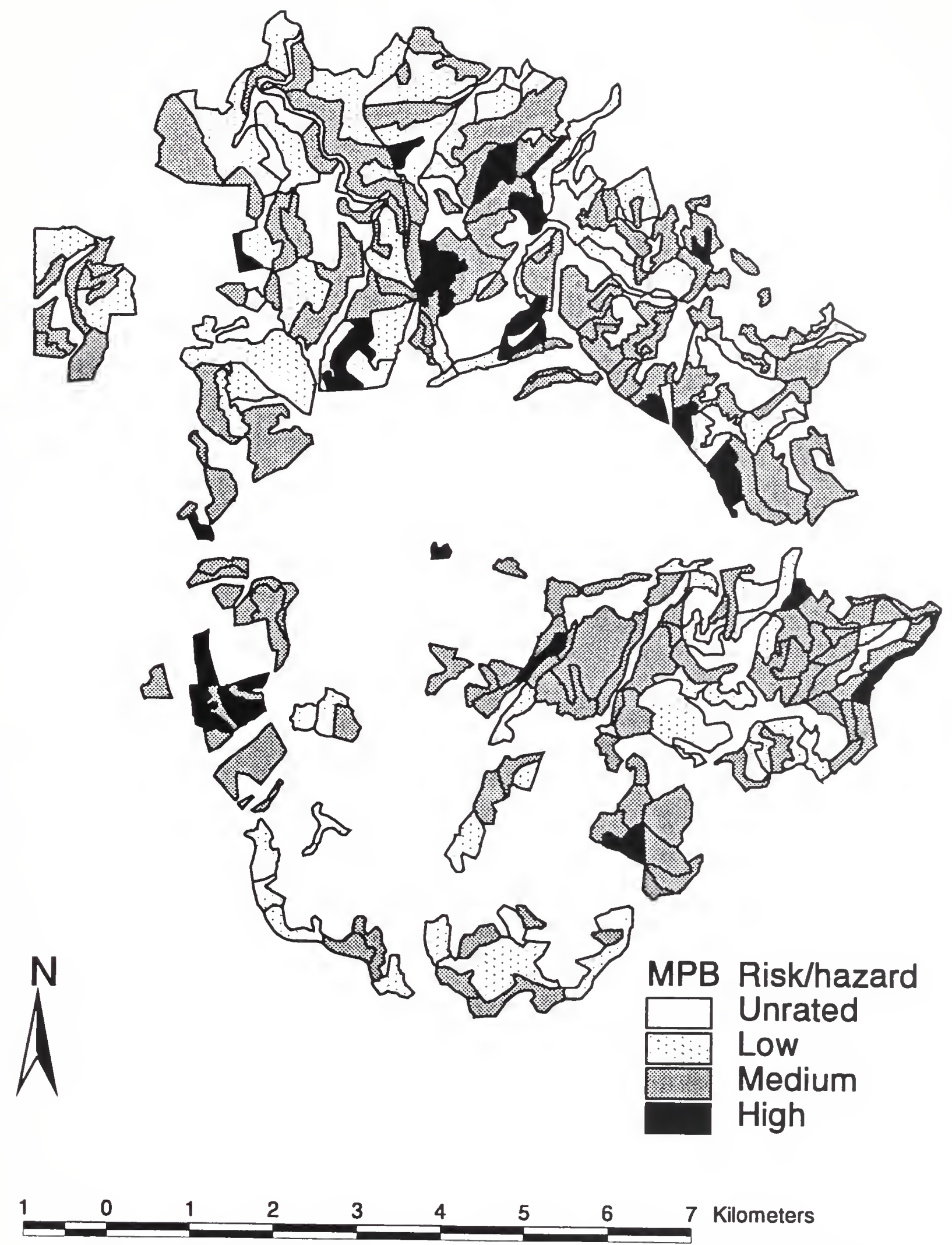

Fig. 22. Mountain pine beetle risk/hazard ratings displayed on geographic information system (GIS) maps as generated by the PONBUG model for the Tollgate project area. 



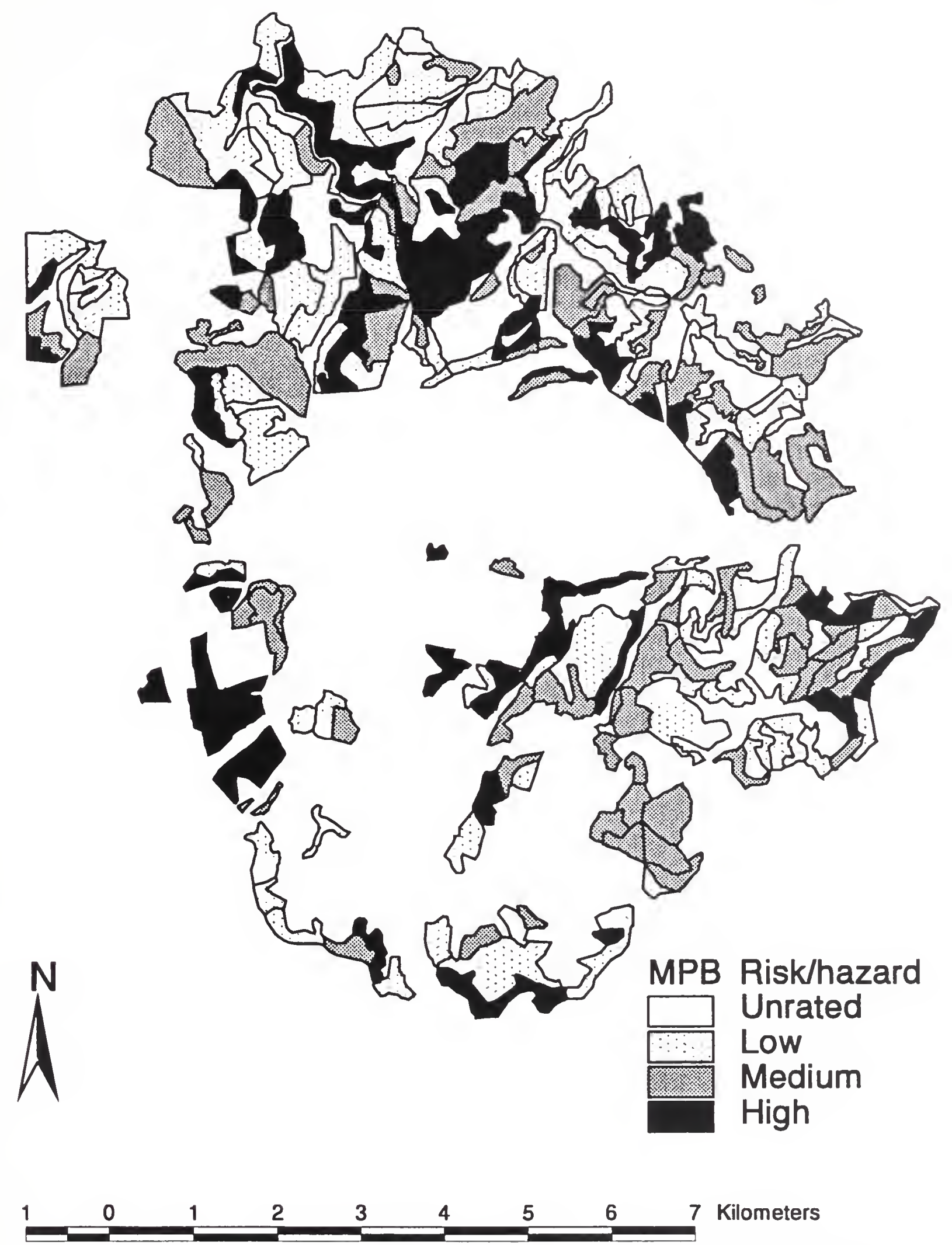

Fig. 23. Mountain pine beetle risk/hazard ratings displayed on geographic information system (GIS) maps as generated by the Schmid model for the Tollgate project area. 



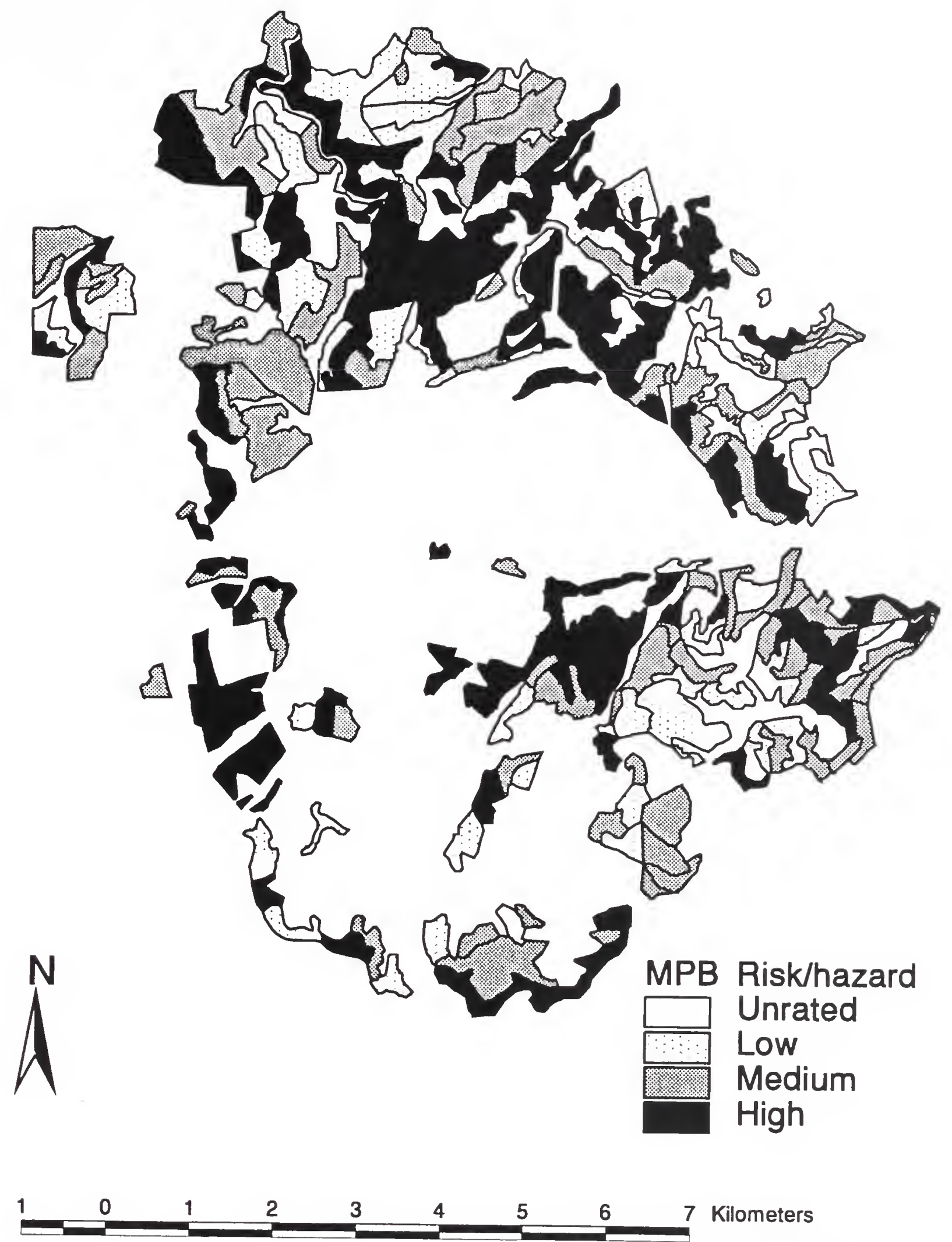

Fig. 24. Mountain pine beetle risk/hazard ratings displayed on geographic information system (GIS) maps as generated by the Schmid 5 model for the Tollgate project area. 



\section{REFERENCES}

Lessard, G. 1982. Factors affecting ponderosa pine stand susceptibility to mountain pine beetle in the Black Hills. USDA Forest Service, Technical Report R2-26. Rocky Mountain Region, Timber, Forest Pest, and Cooperative Forestry Management, Lakewood, CO. 16 p.

Sartwell, C. and R.E. Stevens. 1975. Mountain pine beetle in ponderosa pine: prospects for silvicultural control in second-growth stands. Journal of Forestry 73(3): 136-140.

Stevens, R.E., W.F. McCambridge and C.B. Edminster. 1980. Risk rating guide for mountain pine beetle in Black Hills ponderosa pine. USDA Forest Service, Research Note RM-385. Rocky Mountain Forest and Range Experiment Station, Ft. Collins, CO. 2 p.

Schmid, J.M. and S.A. Mata. 1992. Stand density and mountain pine beetle-caused tree mortality in ponderosa pine stands. USDA Forest Service, Research Note RM-515. Rocky Mountain Forest and Range Experiment Station, Ft. Collins, CO. 4 p

Schmid, J.M., S.A. Mata, and R.A. Obedzinski. 1994. Hazard rating ponderosa pine stands for mountain pine beetles in the Black Hills. USDA Forest Service, Research Note RM-529. Rocky Mountain Forest and Range Experiment Station, Ft. Collins, CO. 4 p. 


